\title{
Lack of Galactose or Galacturonic Acid in Bradyrhizobium japonicum USDA 110 Exopolysaccharide Leads to Different Symbiotic Responses in Soybean
}

\author{
Juan Ignacio Quelas, ${ }^{1}$ Elías J. Mongiardini, ${ }^{1}$ Adriana Casabuono, ${ }^{2}$ Silvina L. López-García, ${ }^{1}$ \\ M. Julia Althabegoiti, ${ }^{1}$ Julieta M. Covelli, ${ }^{1}$ Julieta Pérez-Giménez, ${ }^{1}$ Alicia Couto, ${ }^{2}$ and Aníbal R. Lodeiro ${ }^{1}$ \\ ${ }^{1}$ Instituto de Biotecnología y Biología Molecular (IBBM), Departamento de Ciencias Biológicas, Facultad de Ciencias Exactas, \\ Universidad Nacional de La Plata y CCT La Plata-CONICET, Calles 47 y 115 (1900) La Plata, Argentina; ${ }^{2}$ Centro de \\ Investigaciones en Hidratos de Carbono (CIHIDECAR), Departamento de Química Orgánica, Facultad de Ciencias Exactas \\ y Naturales, Universidad de Buenos Aires. Pabellón II, 3er Piso. Ciudad Universitaria (1428) Buenos Aires, Argentina
}

Submitted 21 May 2010. Accepted 28 June 2010.

Exopolysaccharide (EPS) and lipopolysaccharide (LPS) from Bradyrhizobium japonicum are important for infection and nodulation of soybean (Glycine max), although their roles are not completely understood. To better understand this, we constructed mutants in $B$. japonicum USDA 110 impaired in galactose or galacturonic acid incorporation into the EPS without affecting the LPS. The derivative LP 3010 had a deletion of $l s p L-u g d H$ and produced EPS without galacturonic acid whereas LP 3013, with an insertion in exoB, produced EPS without galactose. In addition, the strain LP 3017, with both mutations, had EPS devoid of both galactosides. The missing galactosides were not replaced by other sugars. The defects in EPS had different consequences. LP 3010 formed biofilms and nodulated but was defective in competitiveness for nodulation; and, inside nodules, the peribacteroid membranes tended to fuse, leading to the merging of symbiosomes. Meanwhile, LP 3013 and LP 3017 were unable to form biofilms and produced empty pseudonodules but exoB suppressor mutants were obtained when LP 3013 plant inoculation was supplemented with wild-type EPS. Similar phenotypes were observed with all these mutants in $G$. soja. Therefore, the lack of each galactoside in the EPS has a different functional effect on the $B$. japonicum-soybean symbiosis.

The $\mathrm{N}_{2}$-fixing symbiosis between soil rhizobia and legume plants develops by a delicate process whereby rhizobia infect and nodulate the legume roots, whereas plant defense reactions against root bacterial infection must be selectively prevented (Jones et al. 2007). This process requires complex bacteriaplant recognition, in which rhizobial surface polysaccharides seem to be responsible for plant defense inhibition (Niehaus et al. 1993, 1997; Parniske et al. 1994). Recognition of rhizobial surface polysaccharides is achieved by plant lectins, which are involved in determining host specificity (Hirsch 1999). In addition, these polysaccharides protect rhizobia from biotic and

Corresponding author: A. R. Lodeiro; Telephone: +54 221.422.9777; Email: lodeiro@biol.unlp.edu.ar

* The $\boldsymbol{e}$-Xtra logo stands for "electronic extra" and indicates that three supplementary figures are published online. abiotic stresses, contribute to rhizobial adhesion to root surfaces, and take part in biofilm formation (Fraysee et al. 2003; Skorupska et al. 2006).

The symbiosis is characterized by the formation of root nodules, which diverge in morphology and histology in different legume species (Doyle 1998). The most extensively studied nodules are the determinate nodules, which have a round shape without a defined meristem, and the indeterminate nodules, which are elongated and possess an active meristem at their tips (Patriarca et al. 2004). Studies on the role of rhizobial surface polysaccharides in nodule development in diverse species led to the general conclusion that determinate nodule invasion requires lipopolysaccharide (LPS) while indeterminate nodule invasion requires exopolysaccharide (EPS) (Hotter and Scott 1991; Leigh and Coplin 1992; Kannenberg and Brewin 1994; Fraysse et al. 2003, Parada et al. 2006). However, experiments investigating the symbiosis between Bradyrhizobium japonicum and soybean (Glycine max), which forms determinate nodules, indicates that EPS plays a role in soybean nodulation, although this role is not yet well characterized (Parniske et al. 1993; Eggleston et al. 1996; Becker et al. 1998; Karr et al. 2000).

In the $B$. japonicum type strain, USDA 110 , the capsular polysaccharide (CPS) and the EPS have the same composition and structure, differing only in that CPS is anchored to the cell surface while EPS is released into the cell's surroundings (Mort and Bauer 1980, 1982). Given these similarities, we will further refer to both extracellular polysaccharides collectively as EPS. Their structure consists of a polymer of the pentameric repeating unit (O-methyl or O-acetyl) galactose $\alpha(1 \rightarrow 6)$ glucose $\alpha(1 \rightarrow 3)$ glucose $\beta(1 \rightarrow 3)$ O-acetyl galacturonic acid $\alpha(1 \rightarrow 3)$ mannose, which is $\alpha(1 \rightarrow 3)$ linked to the glucose at the nonreducing end of the next repeating unit (Mort and Bauer 1982). Recent observations suggest that either the mannosyl moiety might be present in only one of every three repeating units or there also exists a second EPS without mannose (Quelas et al. 2006). In B. japonicum USDA 110, minor changes in EPS composition were observed according to the bacterial growth state; although the galactosyl substituent is acetylated in exponentially growing bacteria, it is methylated in stationary-phase bacteria. Nevertheless, these changes are important, because they affect the soybean lectin-binding affinity (Mort and Bauer 1980). 
Thus, several mutants unable to incorporate galactose to the EPS or to bind soybean lectin were investigated. By mutagenizing the strain USDA 110, Parniske and associates (1993) obtained the $\Delta \mathrm{P} 22$ deletion mutant, which is unable to synthesize UDP-galactose, produces a shorter EPS devoid of galactosyl residue, but is unaltered in its LPS. Despite this strain being unable to bind soybean lectin, it produces $\mathrm{N}_{2}$-fixing nodules in G. $\max$, although nodulation is delayed and a more concentrated inoculum is required to obtain the same level of nodulation with the mutant as with the wild type (Parniske et al. 1993). In addition, this strain is impaired in nodule invasion in $G$. soja, triggers plant defense reactions in both hosts, and is affected in biofilm formation and attachment to soybean roots (Parniske et al. 1994; Becker et al. 1998; van Rhijn et al. 1998; Pérez-Giménez et al. 2009). However, Becker and associates (1998) found that the mutation, which affects the exoB gene (blr7578) encoding UDP-glucose-4-epimerase, also disrupts the adjacent exoT and exoP genes, which seem to be involved in determining EPS size (Fig. 1). Furthermore, the authors observed that mutants in exoP had a different ratio of high to low molecular weight EPS than the wild type and, depending on the portion of ExoP mutated, it affected nodulation. Therefore, it is still unclear whether the observed nodulation phenotypes and EPS size are due only to a lack of galactose.

The presence of paralogs is rather common in the genome of B. japonicum USDA 110. Thus, in addition to exoB, a functional UDP-glucose-4-epimerase is also encoded by galE (blr5931) (Chang et al. 2008). It is located within a gene cluster related to LPS biosynthesis, unlike exoB, which belongs to a cluster related to EPS biosynthesis (Supplementary Fig. S1). Interestingly, a galE B. japonicum 61A101C mutant displayed a deeply altered LPS (Chang et al. 2008); despite previous studies indicating that, in this strain, the LPS does not have galactosyl residues (Carrion et al. 1990). This LPS mutant produced empty nodules (devoid of bacteria), as has been previously observed for the interactions of other rhizobial LPS mutants with legume hosts that produce determinate nodules. Therefore, the role of UDP-glucose-4-epimerase on surface polysaccharide biosynthesis and its effects on symbiosis need further clarification.

In a different approach, Eggleston and associates (1996) and Karr and associates (2000) looked for impairment of soybean lectin binding in a series of $\operatorname{Tn} 5$ B. japonicum mutants derived from strain 2143. All the selected mutants were delayed in nodulation, and some of them had significantly lower $\mathrm{N}_{2}$-fixing activities. Two of these mutants, named 1251 and 1252 , were further studied in more detail. The most affected in symbiosis was 1252, which had lower amounts of CPS and LPS than the wild type (Karr et al. 2000). In turn, mutant 1251 de- veloped normal nodules (Eggleston et al. 1996). Delays in nodulation correlated with alterations in EPS composition. Both mutants have a novel EPS, containing glucose, galactose or 4-O-methyl-galactose, xylose, and glucuronic acid (instead of galacturonic acid), in a ratio of 1:5:1:1 (Karr et al. 2000). Therefore, the substitution of xylose for mannose or the substitution of glucuronic for galacturonic acid in the composition of mutant EPS might be responsible for the observed nodulation delay. In particular, the acidic carbohydrate might play a fundamental role, because most rhizobial EPS studied so far are acidic (Fraysse et al. 2003; Skorupska et al. 2006). However, the identity of the genes affected by the Tn 5 insertion in the 1251 and 1252 mutants was not reported.

Consequently, it seems that, although both galactose and galacturonic acid may play fundamental roles in the effects of EPS on the B. japonicum-soybean symbiosis, clear definition of this aspect has been hampered by the lack of site-directed mutants affected only in the incorporation of these carbohydrates to the EPS and not in LPS structure or in other genes related to EPS synthesis. The determination of the complete genomic sequence of $B$. japonicum USDA 110 by Kaneko and associates (2002) allows rational planning of mutagenesis to alter specific phenotypes on the basis of an exact knowledge of the genes and gene regions to be disturbed. Hence, we took advantage of this information to obtain new $B$. japonicum USDA 110 site-directed mutants affected only in the incorporation of each of these carbohydrate moieties to the EPS, and evaluated their biofilm-forming ability as well as their effects on nodulation.

\section{RESULTS}

\section{Mutations in B. japonicum USDA 110 EPS synthesis coding genes.}

Previously, we observed that, although the EPS from mutant $\triangle \mathrm{P} 22$ was devoid of galactose, it had regular amounts of galacturonic acid (Quelas et al. 2006). Therefore, we proposed that, instead of starting from UDP-galactose, the synthesis of the activated sugar UDP-galacturonic acid should be carried out by the oxidation of UDP-glucose to UDP-glucuronic acid and further epimerization to UDP-galacturonic acid. Such a pathway was already described in the fast-growing rhizobia Sinorhizobium meliloti and Rhizobium leguminosarum bv. viceae for the synthesis of their capsular polysaccharide or LPS, respectively (Keretsz et al. 1998; Laus et al. 2004). Thus, in the B. japonicum USDA 110 genomic sequence (Kaneko et al. 2002), we found two open reading frames (ORF), blr2383 and bll8129, annotated as putative $u g d H$ (UDP-glucose-6-dehydrogenase) genes, and another two ORF, blr2382 and bll5920, an-

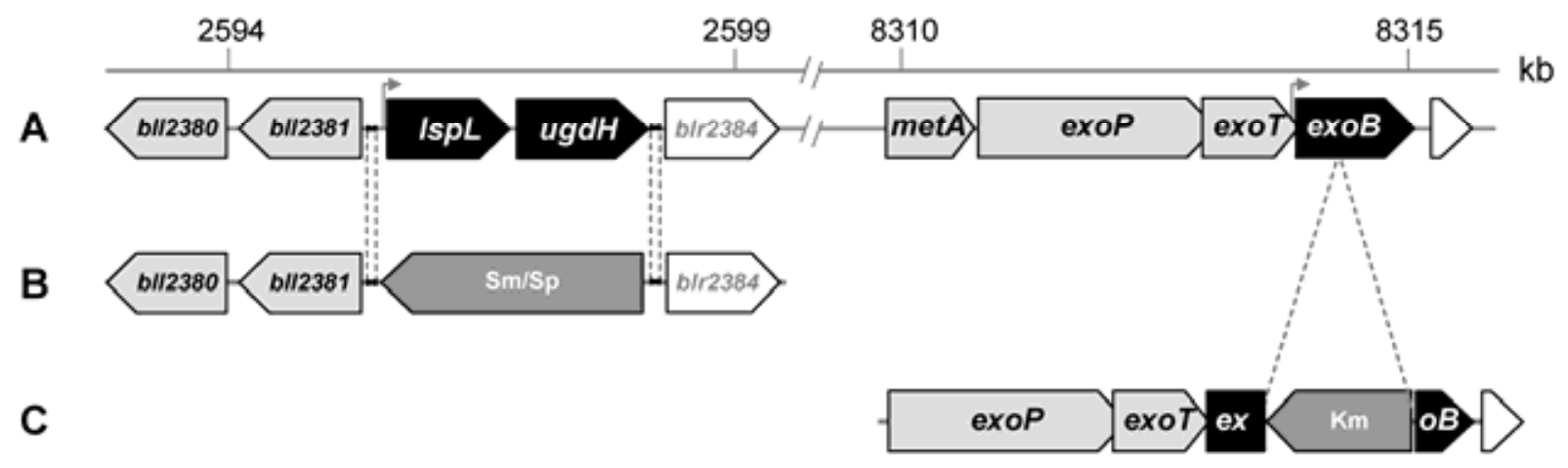

Fig. 1. Schematic genetic map of $l s p L$ (blr2382), ugdH (blr2383), exoB (blr7578), and surrounding genes of Bradyrhizobium japonicum, and the location of mutations performed in this study. A, Wild-type USDA 110. B, Deletional mutant LP 3010. C, Insertional mutant LP 3013 . Putative promoters are indicated by arrowheads. Black boxes: targeted genes; dark gray boxes: kanamycin- or streptomycin-spectinomycin resistance-inserted genes; light gray boxes: genes related with exopolysaccharide (EPS) synthesis; white boxes: genes with no relation to EPS synthesis. 
notated as putative lspL (UDP-glucuronic acid-4-epimerase) genes. The nucleotide sequences of blr2383 and bll8129 were 99\% identical, whereas those of blr2382 and bll5920 were $74 \%$ identical. We looked for possible promoter sequences with BPROM (Softberry website) and found promoters with known transcription factor binding sites upstream of blr2382 (purR) and bll8129 (crp), and a putative promoter upstream of bll5920. In addition, by employing Neural Network Promoter Prediction (NNPP), we also found a putative promoter sequence upstream of blr2383. To predict ribosome-binding sites (RBS) we employed the Comprehensive Microbial Resource website (CMR) and found RBS downstream of both the blr2382 and the blr2383 promoters but not near the other ORF. Moreover, blr2382 and blr2383 are contiguous in a gene cluster that might be related to EPS synthesis and assemblage. Given this genomic context and the finding of recognizable promoters and RBS, we decided to create a deletion in both blr2382 and blr2383 by replacing the DNA region between bases 2,595,605 and 2,597,844 (Kaneko et al. 2002) with a $\Omega$-streptomycinspectinomycin (Sm-Sp) interposon. We obtained three independent clones: LP 3010, LP 3011, and LP 3012 (Fig. 1) (Supplementary Fig. S2A through C). After growth in Götz minimal medium, all of them gave mucoid colonies that, similarly to USDA 110, did not stain with Congo Red but produced only 6 to 14\% of the EPS of the wild type. Data from LP 3010 are shown in Figure 2.

The $\operatorname{exoB}$ gene was previously characterized by Becker and associates (1998) and coincided with ORF blr7578. To mutagenize it, we inserted a kanamycin $(\mathrm{Km})$-resistance cassette (nptI from Tn 903, 1,240 bp), in reverse orientation with respect to blr7578, into the PstI site at base 8,314,648 (Kaneko et al. 2002). Four clones were selected and named LP 3013, LP 3014, LP 3015, and LP 3016 (Fig. 1). These mutants formed rough colonies that stained red with Congo Red, as previously observed with $\triangle \mathrm{P} 22$, and their EPS production was 17 to $24 \%$ of that of the wild type. Representative data from LP 3013 are shown in Figure 2.

Furthermore, we obtained a double mutant affected in both ugdH-lspL and $e x o B$ by employing the same procedure we used to obtain exoB mutants but carried out with LP 3010 as the recipient. The double mutant LP 3017 gave colony morphology similar to that of the exoB mutants, with $23 \%$ EPS production with respect to the wild type (Fig. 2).

For further characterization, we chose the LP 3010 and LP 3013 strains as representatives of a $u g d H$-lspL deletion and an exo $B$ insertion, respectively.

\section{Analysis of surface polysaccharides.}

The different EPS samples were dialyzed with a $14.5-\mathrm{kDa}$ cut-off membrane against double-distilled water, lyophilized,

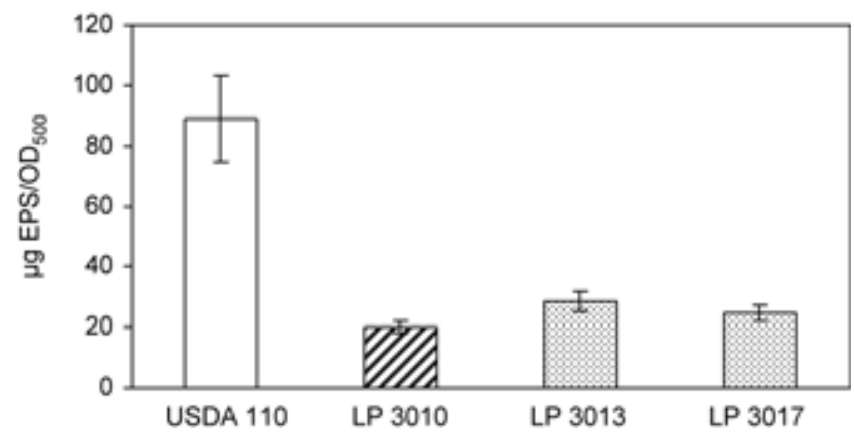

Fig. 2. Exopolysaccharide production by Bradyrhizobium japonicum. White bar: wild-type strain; crossed bar: mutant LP 3010 (lspL-ugdH); dotted bars: mutants LP 3013 (exoB) and LP 3017 (lspL-ugdH-exoB). Error bars represent standard deviation $(n=3 ; P<0.05)$. and weighed. When EPS from LP 3013 and LP 3017 were dialyzed with a $3.5-\mathrm{kDa}$ cut-off membrane, no differences in the retained masses were observed.

Gravimetrically determined mass was consistent with data obtained from the anthrone reaction and also with results from high-performance anion-exchange chromatography coupled to a pulse amperometric detector (HPAEC-PAD) in all samples. Accordingly, Bradford protein determination was negative in all samples.

Composition analysis of these EPS samples was performed by HPAEC-PAD. At least five independent experiments (starting from different batch cultures) were carried out with each mutant (Fig. 3). The analysis confirmed that, on the one hand, the $l s p L-u g d H$ deletion led to an absence of galacturonic acid in the EPS, without replacement by any other acidic sugar. However, an additional peak (marked as " $\mathrm{X}$ " in chromatograms) appeared with a retention time higher than that of galacturonic acid. It is known that, in B. japonicum USDA 110 EPS, galacturonic acid is modified by acetylation (Mort and Bauer 1982). However, prior to their analysis by HPAEC-PAD, samples were subjected to a chemical processing that removes acetyl substituents. Nevertheless, this peak was absent in all mutants without galacturonic acid and, therefore, it might represent an as-yet-unknown galacturonic acid modification. Meanwhile, the composition of neutral sugars remained unaffected. On the other hand, the $n p t I$ insertion into exoB led to a lack of galactose in the EPS, again without replacement by any other sugar. As expected, EPS from the double mutant was devoid of both galactose and galacturonic acid (Fig. 3). Loss of viability in Götz minimal medium was not observed for any mutant. Trans complementation with pIQ08 (with the complete blr7578 gene) and pIQ15 (with the complete blr2382 and -83 genes) restored normal composition to both single-mutant EPS. Moreover, LP 3010 EPS did not migrate at all in polyacrylamide gel electrophoresis (PAGE), in contrast to the wild-type EPS, which migrated to the positive pole, thus corroborating that LP 3010 EPS was not acidic (not shown).

To check whether these mutations affected LPS structure, this cell surface component was isolated and analyzed by sodium dodecyl sulfate (SDS)-PAGE. We observed that the electrophoretic LPS band patterns from all mutants were indistinguishable from the wild type (Fig. 4) and were similar to other $B$. japonicum wild-type LPS profiles, showing characteristic doublets in the higher molecular weight bands, with a separation pattern similar to that observed before (Puvanesarajah et al. 1987; Carrion et al. 1990; Chang et al. 2008). However, this similarity in electrophoretic profiles does not rule out the possibility that LPS composition could be altered. Although $B$. japonicum USDA 110 LPS does not contain galactose, it does have unidentified uronic acids (Puvanesarajah et al. 1987). Therefore, we separated the oligosaccharidic portion of the LPS by hydrolyzing the glycosidic bond between the polysaccharide and the lipid A with $1 \%$ acetic acid at $100^{\circ} \mathrm{C}$ as described by D'Antuono and associates (2005). Analysis of the monosaccharide components by HPAEC-PAD showed that both USDA 110 and LP 3010 LPS had galacturonic acid in similar amounts (not shown). Although surprising, this result indicates that, regarding this sugar, LPS composition was unaffected in the mutants.

\section{Biofilm formation.}

Fujishige and associates (2006) and Rinaudi and González (2009) reported that, in addition to other functions, EPS is necessary for biofilm formation in $S$. meliloti. Because our $B$. japonicum mutants had lower EPS contents than the wild type, we tested whether these mutants were also impaired to form biofilms, employing the methodology described by these au- 
thors. We noted that $\Delta$ P22, LP 3013 (exoB), and LP 3017 (lspL$u g d H-e x o B)$ were, indeed, impaired in biofilm formation. In contrast, the LP $3010 u g d H$-lspL deletion mutant did form biofilms in degrees similar to the wild type, USDA 110 (Fig. 5).

\section{General description of nodulation.}

Each mutant showed a markedly different phenotype in soybean Don Mario cv. 4800. Whereas LP 3010 (lspL-ugdH) produced macroscopically normal nodules, although in lower numbers than the wild type, LP 3013 (exoB) produced few, small, and white pseudonodules. The phenotype produced by LP 3010 was also observed with clones LP 3011 and LP 3012 (lspL-ugdH), while the phenotype produced by LP 3013 was also produced by clones LP 3014, LP 3015, and LP 3016 (exoB). The nodulation by the double mutant LP 3017 was similar to that by strain LP 3013, indicating that, for this trait, the mutation in $\operatorname{exoB}$ was epistatic to $l s p L-u g d H$. In agreement with these nodulation phenotypes, we observed that plants nodulated with LP 3010 grew normally in the absence of combined $\mathrm{N}$ sources, with green leaves and a shoot dry weight similar to USDA 110 , showing that $\mathrm{N}_{2}$ fixation was active. In contrast, plants nodulated with LP 3013 or LP 3017 and cultivated under the same conditions were smaller and had pale green leaves, similar to uninoculated controls, thus indicating that these plants were unable to fix $\mathrm{N}_{2}$. These phenotypes were observed also in $G$. soja cv. PI339871A (Fig. 6). In addition, the LP 3013 nodulation phenotype was also observed in the $G$. max cvs. Don Mario 3100, Don Mario 4600, and A7321RG. Given these differences in nodulation phenotype among the mutants, further details are provided separately.

\section{Nodulation of $l s p L-u g d H$ mutants.}

To evaluate infectivity, we inoculated soybean plants cultivated in plastic growth pouches with USDA 110 or LP 3010 in the logarithmic growth phase with rhizobia at rates of either
5,000 or $500,000 \mathrm{CFU} \mathrm{ml} \mathrm{m}^{-1}$ and recorded nodule distribution along the primary roots (Bhuvaneswari et al. 1980). Nodulation parameters shown in Table 1 indicate that LP 3010 tended to be less infective at both inoculum densities. In agreement with this diminished infectivity, when soybean plants that were cultivated for 23 days in vermiculite pots were co-inoculated in a 1:1 ratio with LP 3010 and USDA 110 (with both strains in the logarithmic growth phase), the mutant strain occupied only $10 \%$ of all nodules, which differed significantly $(P<0.05)$ from the null hypothesis of 50:50\% occupation.

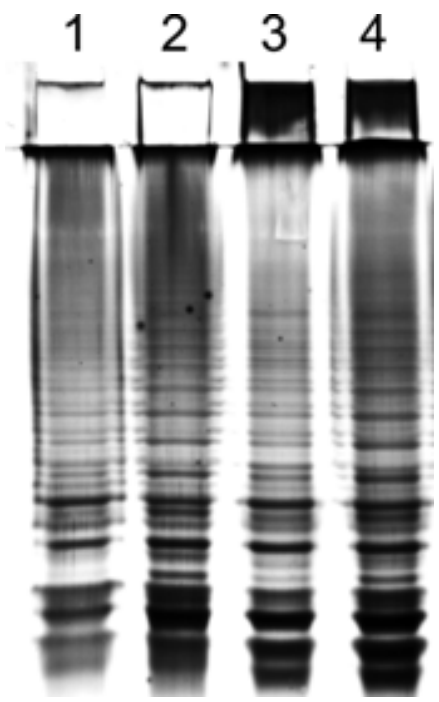

Fig. 4. Polyacrylamide gel electrophoresis sodium dodecyl sulfate lipopolysaccharide profiles of Bradyrhizobium japonicum. Lane 1: USDA 110; lane 2: LP 3010 (lspL-ugdH); lane 3: LP 3013 (exoB); lane 4: LP 3017 (lspL-ugdH-exoB).
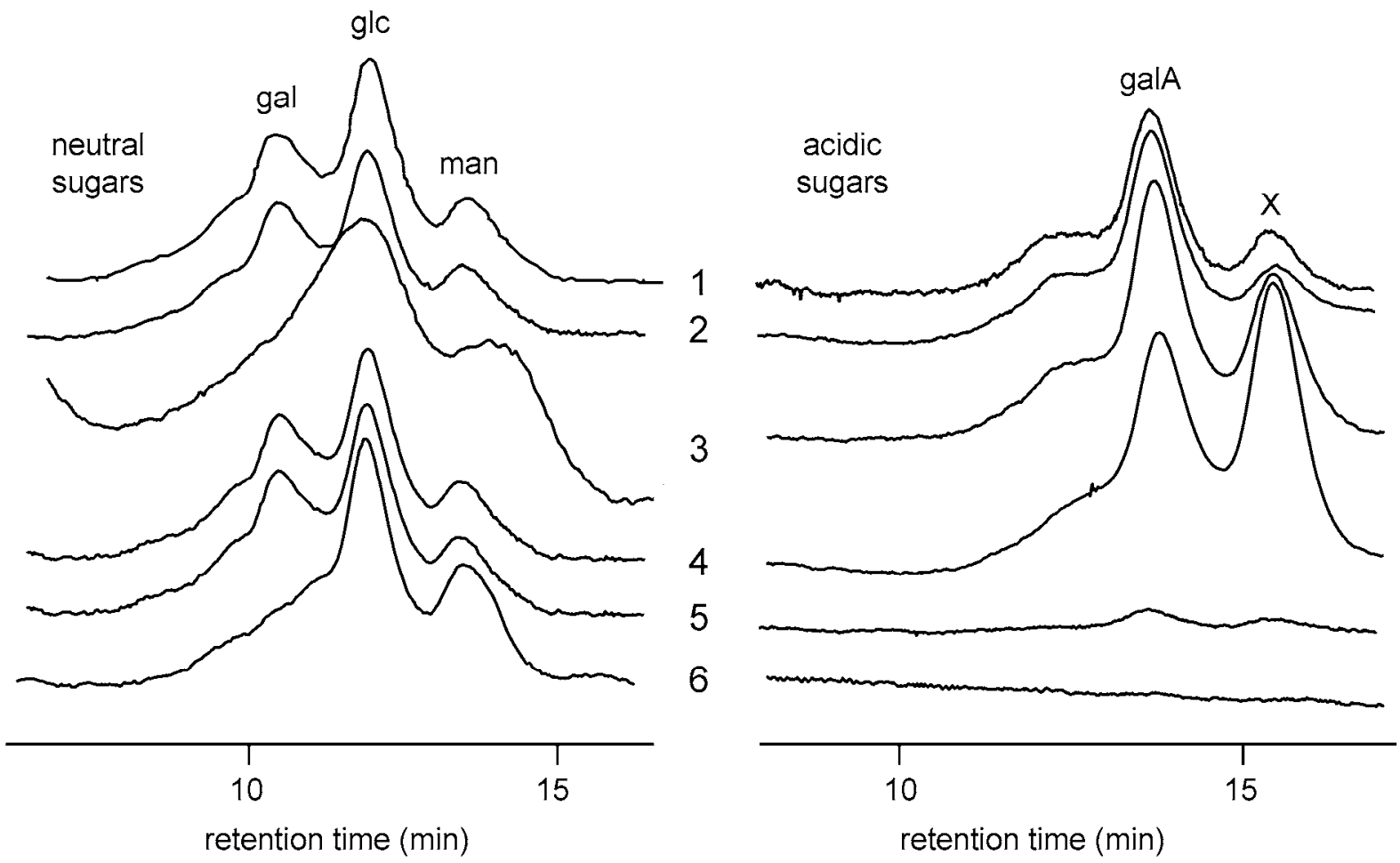

Fig. 3. High-performance anion-exchange chromatography coupled to a pulse amperometric detector chromatograms for neutral and acidic sugars from digested exopolysaccharide obtained from cultures of Bradyrhizobium japonicum. 1: USDA 110; 2: LP 3010 (lspL-ugdH) complemented with pIQ15 (carrying wild-type lspL-ugdH genes); 3: LP 3013 (exoB); 4: LP 3013 complemented with pIQ08 (carrying wild-type exoB gene); 5: LP 3010; 6: LP 3017 (lspL-ugdH-exoB). Hexoses corresponding to each peak are indicated above it; gal: galactose; glc: glucose; man: mannose; galA: galacturonic acid: X, unknown compound. 
Under the microscope, nodules produced by the mutant displayed multiple vacuoles located in the perinuclear region of infected cells, as well as enlarged cell walls in the outermost cortical cells, resembling symptoms produced by other EPS mutants (Fig. 7B and D). In addition, in repeated experiments. we observed that the nodule ultrastructure also differed. In nodules formed by LP 3010, we observed peribacteroidal membrane fusions, which led to symbiosomes with approximately 7 to 10 bacteroids inside. However, both the wild type and LP 3010 complemented with pIQ15 carrying wild-type $l s p L$ $u g d H$ genes gave only three to four bacteroids per symbiosome (Fig. 8), as usually observed for young determinate nodules (Fedorova et al. 1999). Although LP 3017 formed empty nodules, complementation of this strain with pIQ08 carrying the complete $e x o B$ gene gave nodules with structure similar to those produced by LP 3010 (Fig. 8D).

To evaluate the effect of this mutation on plant growth, we inoculated 20 soybean plants with USDA 110, LP 3010, LP 3011 , or LP 3012 and cultivated these plants for 63 days in vermiculite pots with $\mathrm{N}$-free Fåhraeus modified solution (FMS). Then, we collected the shoots and determined their dry weights, which were $1.05 \pm 0.08,1.10 \pm 0.06,0.89 \pm 0.05$, and $1.13 \pm 0.09$ average $\mathrm{g}$ plant $^{-1} \pm$ mean standard error, respectively. Because the uninoculated control gave a shoot dry weight of $0.69 \pm 0.03$, the response of the inoculated plants indicated that, as expected, $\mathrm{N}$ was the limiting nutrient for growth. Therefore, these shoot dry weight values may be considered to be indirect estimates of $\mathrm{N}_{2}$-fixing abilities of the wild-type and $l s p L-u g d H$ mutant strains. These results indicate that, despite the observed defects in nodulation and symbiosome morphology produced by the mutants, $\mathrm{N}_{2}$ fixation seemed unaffected. This same trend was observed in repeated experiments.

\section{Nodulation of exoB mutants.}

The exoB mutant strains LP 3013 and LP 3017 produced small and white nodules, which seemed inactive for $\mathrm{N}_{2}$ fixation, in contrast to nodulation by the previously characterized exoPexoT-exoB mutant, $\triangle \mathrm{P} 22$, which produces normal nodules and fixes $\mathrm{N}_{2}$ in soybean (Becker et al. 1998; Quelas et al. 2006). To obtain additional detailed information, the histology of nodules from G. max cv. Don Mario 4800 was examined. As expected from their external appearance, the central tissue of nodules produced by LP 3013 and LP 3017was found to be not occupied by bacteria and, in addition, vascular bundles were observed there. This structure more resembles root than nodule structure, as described previously for pseudonodules of common bean and soybean (Vandenbosch et al. 1985; Stanley et al. 1986) (Fig. 7E and F). In agreement with this finding, rhizobia could not be recovered on yeast extract-mannitol agar (YMA) plates from these nodules, unlike nodules produced by USDA 110 or $\triangle \mathrm{P} 22$. Both the nodulation-defective phenotypes of LP 3013 and LP 3017 were complemented with pIQ08 carrying the intact $e x o B$ gene and, thus, nodulation defects were found to coincide with the alteration in EPS (Fig. 7G and $\mathrm{H}$ ).

When soybean plants were inoculated with LP 3013 supplemented with galactose, there was no effect, in agreement with previous observations by Becker and associates (1998). However, when $50 \mu \mathrm{g}$ of wild-type EPS per plant was added, the plants were still pale green; however, one pink nodule per plant appeared in the taproots (not shown). Rhizobia could be obtained from these nodules, and their colony morphology and antibiotic resistance were coincident with LP 3013. In addition, specific polymerase chain reaction (PCR) carried out with extF/KmR and KmF/extR primers (Table 2) gave the same band pattern previously observed for the mutant LP 3013 (Supplementary Fig. S3B), thus confirming that the $\operatorname{exoB}$ mutation was unaltered. However, when soybean plants were inoculated with these recovered rhizobia without the addition of EPS, functional, pink nodules were produced, and the plants grew as green as the wild type. Therefore, EPS complementation allowed the recovery of LP 3013 suppressor mutants, although with low efficiency. The nature of these mutations is still unknown.

When inoculated on plants in plastic growth pouches, LP 3013 did not nodulate the roots. This result might be explained by the more stressful condition to which plants are subjected in plastic growth pouches compared with vermiculite pots. Given this result, we performed neither infectivity nor competitiveness studies with this mutant.

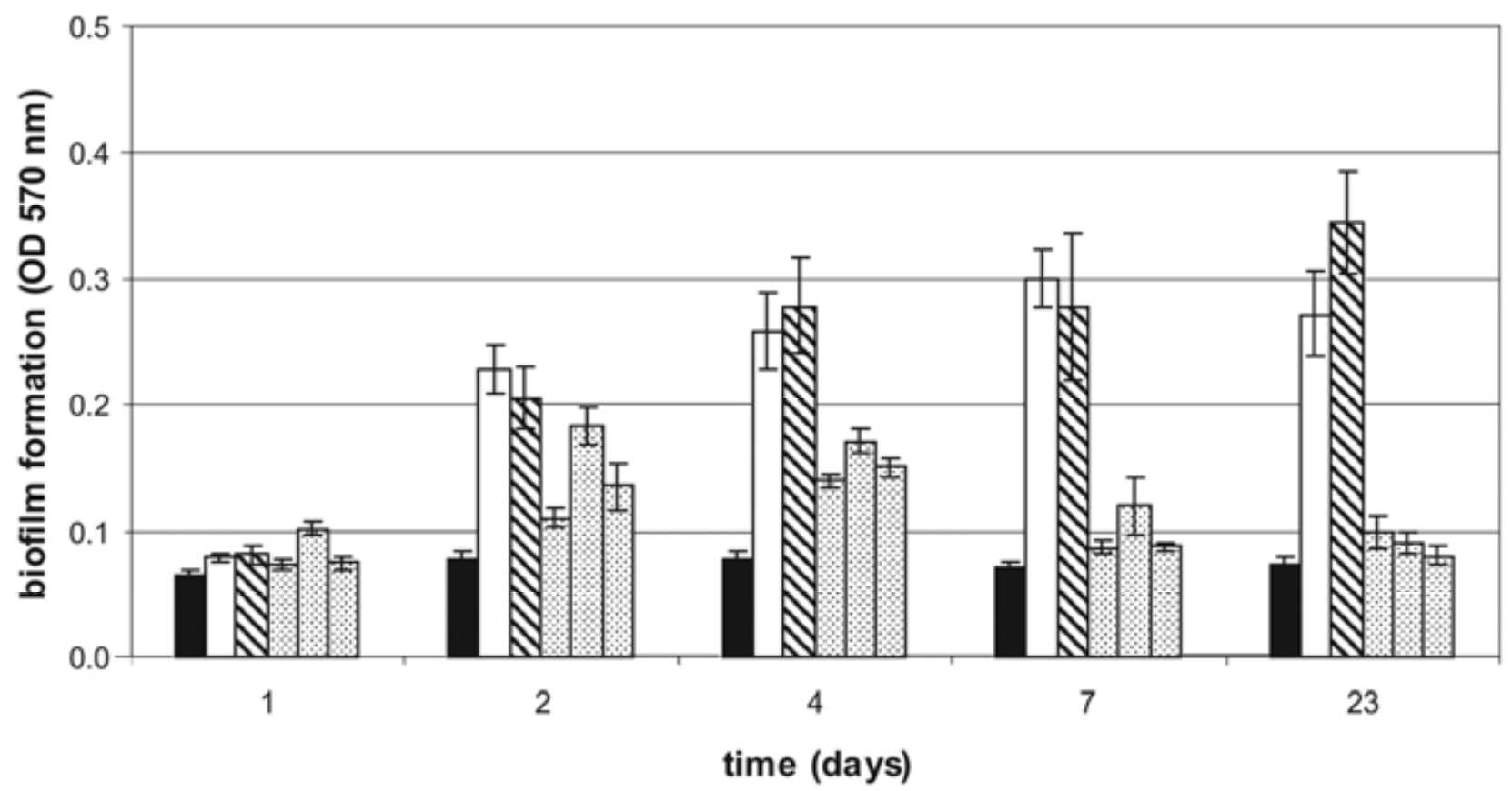

Fig. 5. Biofilm formation by Bradyrhizobium japonicum at the times indicated. Black bars: control without bacteria. White bars: USDA 110 . Crossed bars: LP 3010 (lspL-ugdH). Dotted bars, from left to right: LP 3013 (exoB), LP 3017 (lspL-ugdH-exoB), $\Delta \mathrm{P} 22$ (exoP-exoT-exoB). Error bars represent standard deviation $(n=8 ; P<0.05)$. 


\section{DISCUSSION}

Biosynthesis of bacterial surface polysaccharides requires nucleotide sugars as activated building blocks. Thus, in $B$. japonicum, galactose and galacturonic acid are incorporated into the EPS as UDP-sugars, originating from the common precur- sor UDP-glucose. In one pathway, epimerization of UDP-glucose to UDP-galactose is catalyzed by the enzyme UDP-glucose-4-epimerase, encoded by $\operatorname{exoB}$ and galE. In the other pathway, UDP-glucose is oxidized to UDP-glucuronic acid in a reaction catalyzed by UDP-glucose-6-dehydrogenase, which is encoded by $u g d H$ (two paralogs) and further epimerized to
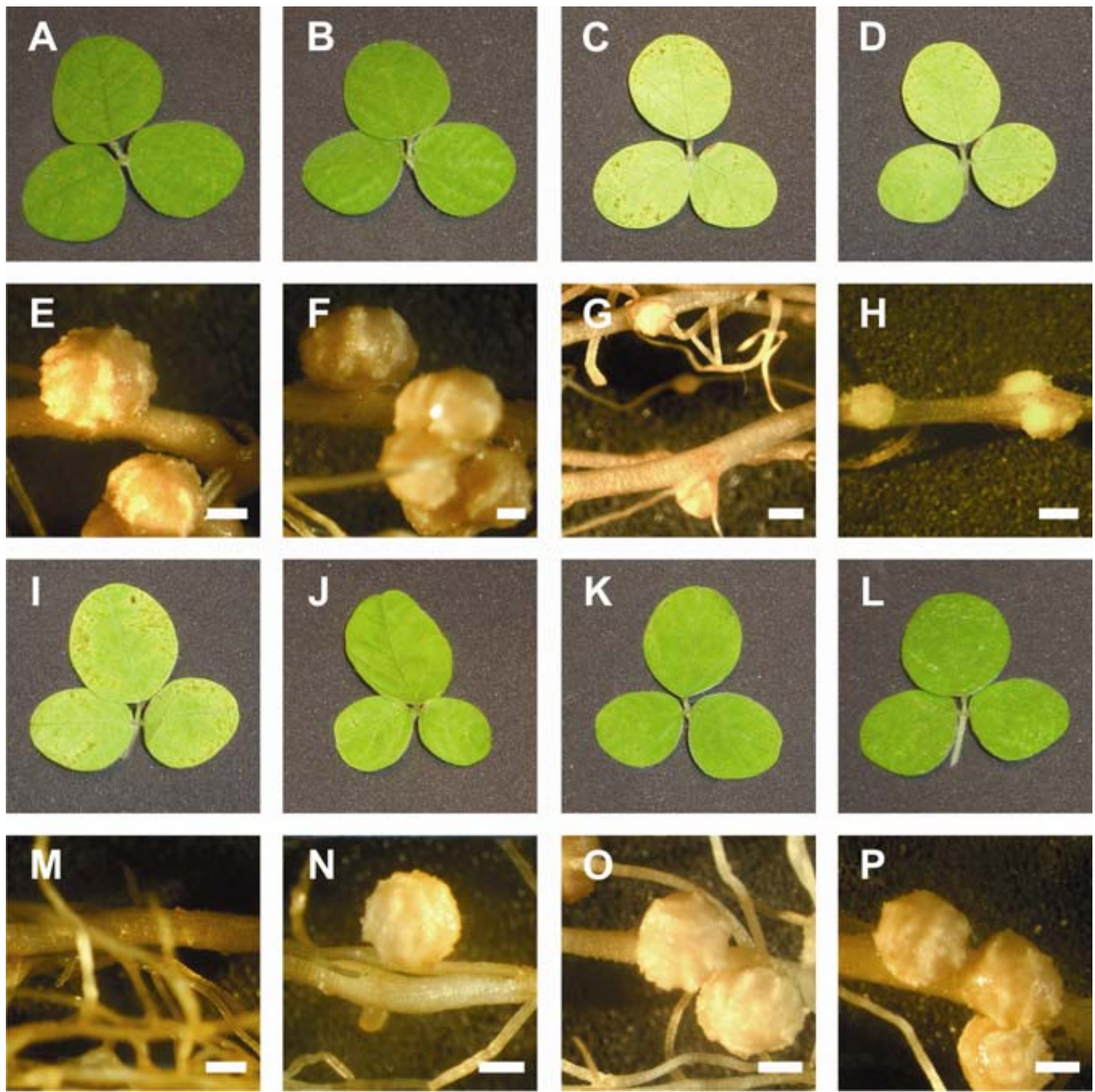

Fig. 6. Leaves and nodules of Glycine soja PI339871A inoculated by Bradyrhizobium japonicum. A and E, USDA 110; B and F, LP 3010; C and G, LP 3013; $\mathbf{D}$ and $\mathbf{H}$, LP 3017; I and M, negative control; J and N, $\triangle \mathrm{P} 22$; $\mathbf{K}$ and $\mathbf{O}$, LP 3013 complemented with pIQ08 (carrying wild-type exoB gene); $\mathbf{L}$ and $\mathbf{P}$, LP 3017 complemented with pIQ08. Bars: $1 \mathrm{~mm}$.

Table 1. Infectivity parameters of Bradyrhizobium japonicum LP 3010 (lspL-ugdH) in comparison with the wild type USDA $110^{\mathrm{a}}$

\begin{tabular}{|c|c|c|c|c|}
\hline \multirow[b]{2}{*}{ Parameter } & \multicolumn{2}{|c|}{ Low inoculum $\left(5 \times 10^{3} \mathrm{CFU} \mathrm{ml}^{-1}\right)$} & \multicolumn{2}{|c|}{ High inoculum $\left(5 \times 10^{5} \mathrm{CFU} \mathrm{ml}^{-1}\right)$} \\
\hline & USDA 110 & LP 3010 & USDA 110 & LP 3010 \\
\hline Nodulated plants (\%) & 93.3 & 78.8 & 97.7 & 60.9 \\
\hline Mean no. of nodules in primary roots of nodulated plants & $3.53 \pm 0.33$ & $2.58 \pm 0.28$ & $4.90 \pm 0.49$ & $2.65 \pm 0.31$ \\
\hline Mean distance of the uppermost nodule to RT mark (RDU) & $-1.77 \pm 0.30$ & $-2.34 \pm 0.65$ & $+0.12 \pm 0.15$ & $-0.20 \pm 0.31$ \\
\hline
\end{tabular}

\footnotetext{
${ }^{a}$ Mean values \pm standard error.

${ }^{\mathrm{b}} \mathrm{RT}=$ root tip and $\mathrm{RDU}=$ relative distance units
} 
UDP-galacturonic acid in a reaction catalyzed by UDP-glucuronic acid-4-epimerase, encoded by $l s p L$ (two paralogs). In both this work and the previous study by Parniske and associates (1993), exoB mutants produced EPS devoid of galactose although, according to Chang and associates (2008), galE should encode an active UDP-glucose-4-epimerase. Likewise, LP 3010 EPS was devoid of galacturonic acid, while its LPS contained this acidic sugar, thus suggesting that the ORF bll5920 (lspL) and bll8129 $(u g d H)$ remained functional. By
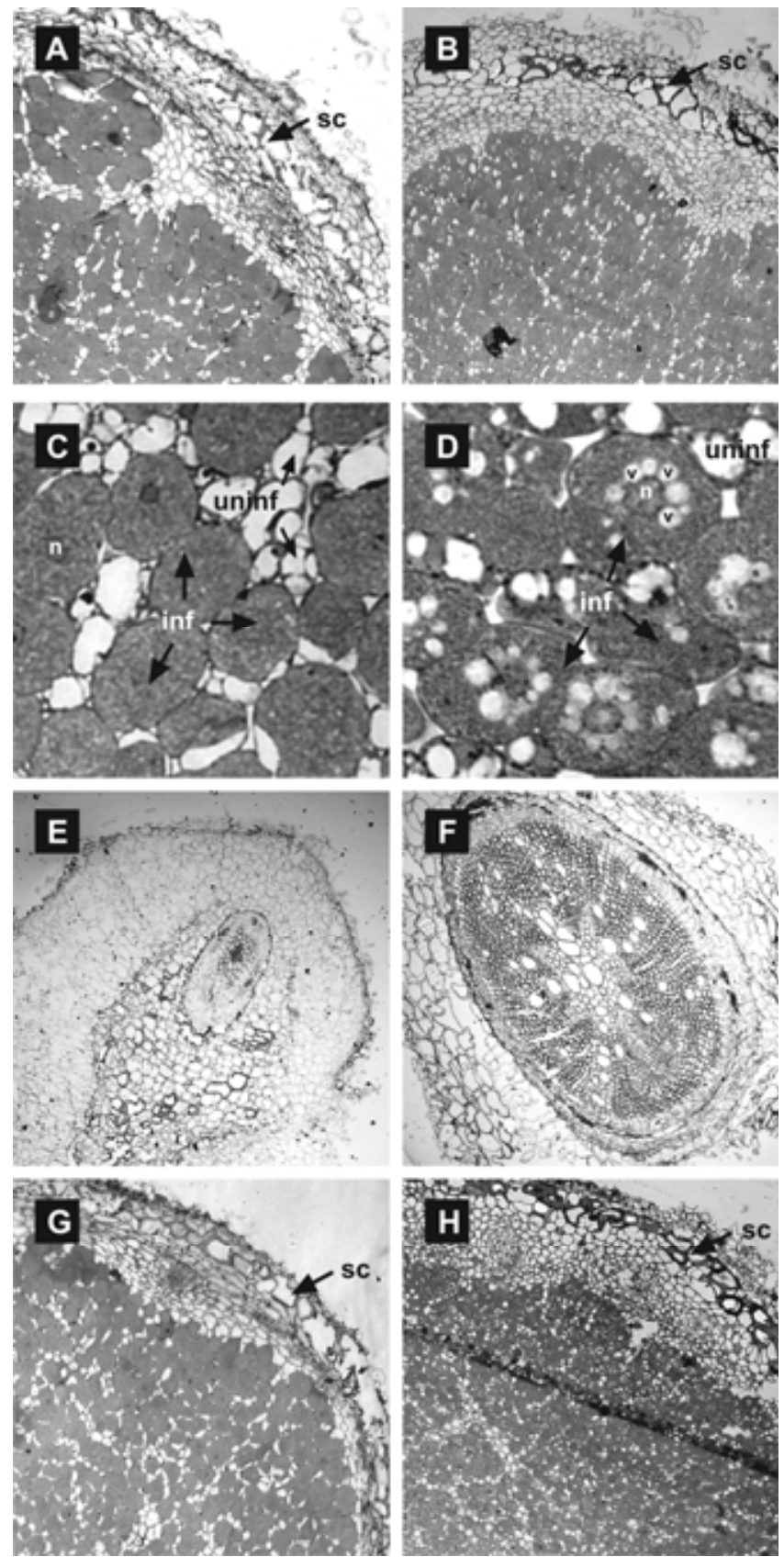

Fig. 7. Histology of nodules from Glycine $\max \mathrm{cv}$. Don Mario 4800 inoculated with A and C, USDA 110; B and D, LP 3010 (lspL-ugdH); E, LP 3013 (exoB); F, LP 3017 (lspL-ugdH-exoB); G, LP 3013 complemented with pIQ08 (carrying wild-type exoB gene); H, LP 3017 complemented with pIQ08. Magnification: $\mathbf{C}$ and $\mathbf{D}, \times 1,000$; in $\mathbf{E}, \times 120$; all others, $\times 400$ A, B, G, and $\mathbf{H}$, Sclerenchymatic cells (sc) are indicated, which display ticker cell walls in the nodules infected by LP 3010 (B) compared with the nodules infected by the double-mutant LP 3017 complemented with pIQ08 (H). $\mathbf{C}$ and $\mathbf{D}$, Infected (inf) and uninfected (uninf) cells are shown with higher magnification. Nuclei (n) are indicated, as well as perinuclear vacuoles (v), which are visible only in nodules produced by LP 3010 (D). examining the location of these genes, we observed that exoB as well as the tandem blr2382-blr2383 (lspL-ugdH) are located in genomic contexts related to EPS biosynthesis, whereas galE and bll5920 (lspL) are in a genomic context of LPS biosynthetic genes. Therefore, each member of each pair of homologous enzymes might function in a different cell compartment or take part in different multienzymatic complexes, so that UDPgalacturonic acid and UDP-galactose may be directly channeled to either EPS or LPS as their polysaccharide sinks.

In $S$. meliloti and R. leguminosarum, EPS biosynthesis starts from a particular carbohydrate moiety attached to a lipid carrier and proceeds by sequentially adding the other moieties to the main chain of the repeating units, which are finally completed with side chains and substituents, polymerized, and exported (Skorupska et al. 2006). In both fast-growing rhizobial species, mutations that prevent addition of one moiety to the repeating unit main chain interrupt biosynthesis. Although the B. japonicum EPS biosynthesis pathway has not yet been experimentally determined, we speculated that it may follow the same general scheme as in fast-growing rhizobia. According to the USDA 110 EPS structure proposed by Mort and Bauer (1982), galacturonic acid is in the main chain, linked by glucose with a $\beta(1 \rightarrow 3)$ bond and to mannose by an $\alpha(1 \rightarrow 3)$ bond. Therefore, it is surprising that LP 3010 EPS was retained by a $14.5-\mathrm{kDa}$ cut-off pore diameter dialysis membrane because, assuming that EPS synthesis starts in mannose, the synthesis of this mutant EPS molecule should be interrupted after addition of the first moiety. The size of the EPS molecule retained in the dialysis bag implies that at least several galacturonic acid-lacking repeating units are condensed. To achieve this polymer, the glucosyl transferase should be able to recognize mannose instead of galacturonic acid at the nonreducing end of the growing repeating unit in LP 3010. Alternatively, the EPS structure should be revised, displacing galacturonic acid from the main chain to a branch.

Although LP 3010, LP 3013, and LP 3017 had low EPS contents, approximately 10 to $20 \%$ of the wild type, only LP 3013 and LP 3017 were defective in biofilm formation, while LP 3010 formed biofilms at a rate similar to that of the wild type. Perhaps EPS neutrality in this mutant allowed for a lack of repulsion among LP 3010 cells, compensating in this way for their lower amount of EPS. Nevertheless, it seems that EPS content per se is not a requirement for biofilm formation, at least in B. japonicum.

The defects in symbiosis observed differed according to the missing galactoside. On the one hand, LP 3010 produced functional nodules but less-nodulated plants than the wild type, with fewer nodules in the primary root of each plant and with a nodule distribution that indicated a delay in the earliest nodu-

Table 2. Primers used in this study

\begin{tabular}{|c|c|c|}
\hline Name & Sequence & Source or reference \\
\hline M13F & GTAAAACGACGGCCAGT & Commercial product \\
\hline M13R & GCGGATAACAATTTCACACAGG & Commercial product \\
\hline $\mathrm{KmF}$ & CATCGGGCTTCCCATACA & Mongiardini et al. 2009 \\
\hline $\mathrm{KmR}$ & TGCCATTCTCACCGGATT & Mongiardini et al. 2009 \\
\hline Sm-Sp & CGGTGGATGACCTTTTGAAT & This study \\
\hline $1 \mathrm{sF}$ & GTGGGTGTCTTACGGTGGG & This study \\
\hline lsR & GCAATGCCAGACCAGGACA & This study \\
\hline $\mathrm{ugF}$ & CTCACCTTCAAGCCCGACAC & This study \\
\hline ugR & GCTGTAGATGTTGCGGAGG & This study \\
\hline lsupF & GCGACAGCACTTGCCACTCT & This study \\
\hline ugdwR & AATCTCCATAGCGGCAGCGA & This study \\
\hline exF & ATGACCGATCCGCAGAAGTA & This study \\
\hline exR & ACCGTAGGCAGGTCAGAGTG & This study \\
\hline $\operatorname{extF}$ & GGATGCAGAAATTCGGACTC & This study \\
\hline extR & AGGCAAGGTGCGGGTGT & This study \\
\hline
\end{tabular}


lation events (Table 1). As a consequence, in competition against the wild-type strain, occupation by the mutant was significantly reduced in comparison with the null hypothesis of 50:50\% occupation by each strain. Even when this null hypothesis did not take into account possible double occupation events, the conclusion of reduced competitiveness of the mutant remains plausible, because an increase of double occupation should tend to increase the detection of nodules occupied by the mutant (which is $\mathrm{Sp}, \mathrm{Sm}$, and chloramphenicol [Cm] resistant) versus the wild type (Cm resistant).

The nodules produced by this mutant had sclerenchymatic cells with thickened walls in their endodermis, as observed previously with EPS mutants that are unable to inhibit plant defense reactions (Parniske et al. 1994). Note that, in addition to nodules formed by LP 3010 (Fig 7B), the sclerenchymatic cells are visible also when LP 3017 was complemented with the wild-type $\operatorname{exoB}$ gene (Fig. $7 \mathrm{H}$ ). The nodule ultrastructure was also altered, in particular at their peribacteroidal membranes, which seemed to fuse (Fig. 8). This observation, performed in three independent experiments, was confirmed by restoring the wild-type appearance in nodules from plants inoculated with the mutant LP 3010 complemented in trans with pIQ15 carrying the wild-type $l s p L-u g d H$ genes, thus discarding the hypothesis that the observed peribacteroidal membrane fusion may be due to differences in staining or contrasting of the samples. This ultrastructure resembles peribacteroidal membrane fusion and symbiosome merging during senescence in determinate common bean nodules (Cermola et al. 2000), which is also consistent with the presence of multiple perinuclear vacuoles in the infected cells (Fig. 7D). During winged bean nodule senescence, large vacuoles are originated by the fusion of vesicles containing electron-dense material that was associated with disorganized bacteroids enclosed in peribacteroidal membranes (Manen et al. 1991). Likewise, rapid bacteroid degradation in perinuclear vacuoles seems to be a manifestation of plant defense (Müller et al. 1995) that, in this regard, might be considered to be an accelerated senescence process. If this is the case, the mutant LP 3010 could have induced a plant defense reaction leading to earlier senescence of noduleinfected cells. For this, it is necessary that the mutant EPS interact in some way with the peribacteroidal membrane. A fibrillar structure containing polysaccharides was observed by Cermola and associates (1994) in common bean nodules and, furthermore, physical association between bacteroid LPS and plant glycoproteins from the peribacteroidal membrane, which may include plant lectins, was observed in the peribacteroidal space between bacteroid and peribacteroidal membranes in indeterminate pea nodules (Bradley et al. 1986; Bolaños et al. 2004). Although it is not clear whether B. japonicum USDA 110 produces EPS inside nodules, ExoB is expressed in bacteroids (Sarma and Emerich 2005). Hence, the above results may indicate that the EPS of LP 3010 interacts in some way with the peribacteroidal membrane, accelerating the process of membrane fusion and symbiosome merging that takes place at the beginning of nodule senescence. This process was also associated with defects in $\mathrm{N}_{2}$ fixation (Cermola et al. 2000;
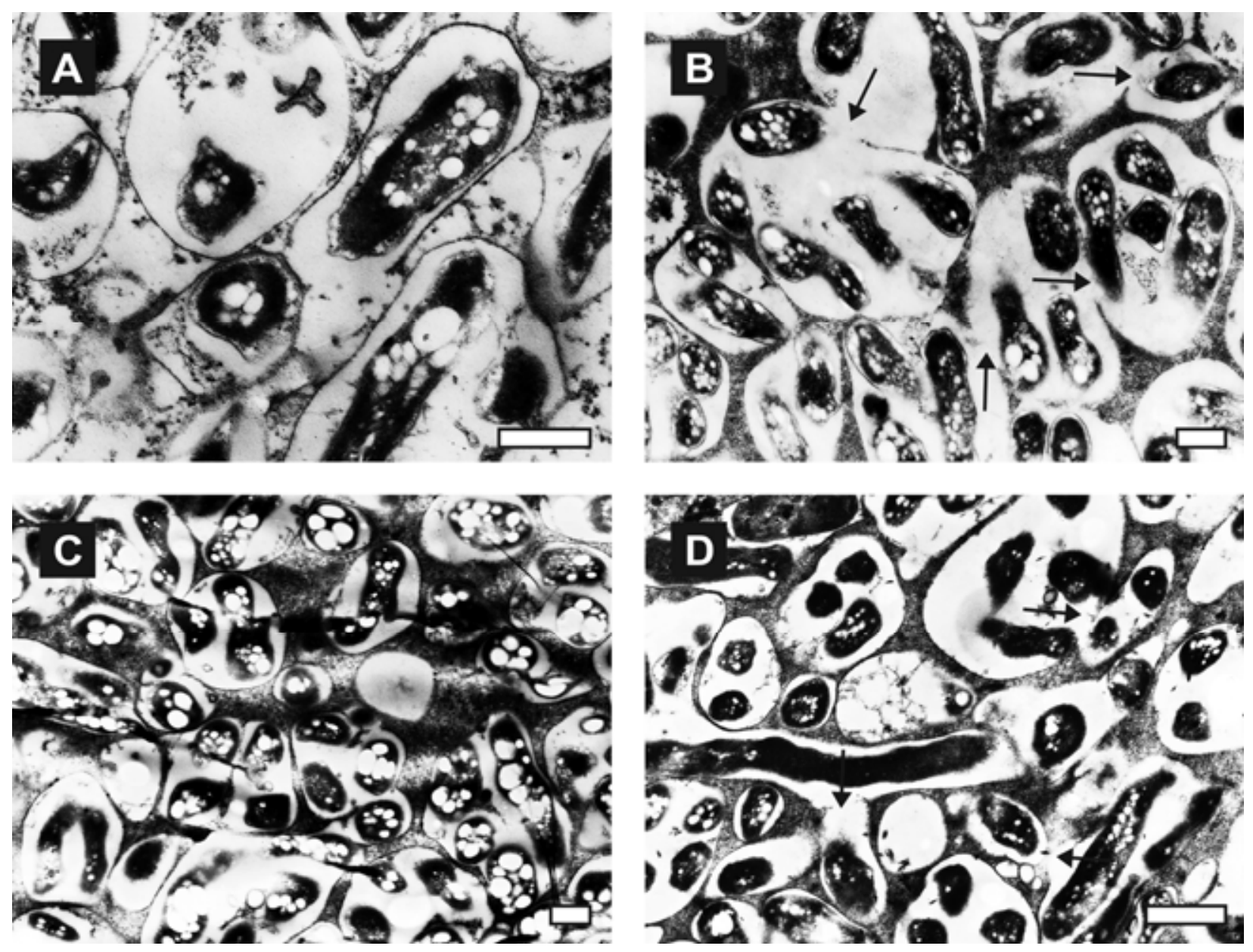

Fig. 8. Electron micrographs of nodules from Glycine max Don Mario 4800 inoculated with A, USDA 110; B, LP 3010 (lspL-ugdH); C, LP 3010 complemented with pIQ15 (carrying wild-type $l s p L$-ugdH genes); D, LP 3017 (lspL-ugdH-exoB) complemented with pIQ08 (carrying wild-type exoB gene). Peribacteroidal membrane fusion is shown by arrows. Bars: $\mathbf{A}$ and $\mathbf{B}, 500 \mathrm{~nm} ; \mathbf{C}$ and $\mathbf{D}, 1 \mu \mathrm{m}$. 
Bolaños et al. 2001) but we could not observe any decrease in soybean dry matter accumulation, even after 63 days of cultivation in vermiculite with an $\mathrm{N}$-free plant nutrient solution.

On the other hand, LP 3013 produced empty nodules in four G. max cultivars as well as in G. soja (Fig. 7), in striking contrast to the previously described exoB mutant $\Delta \mathrm{P} 22$, which produced functional nodules in all these hosts (Fig. 6). Because exoP and exoT are intact in LP 3013, this difference may be related to the activity of their products. Both genes were characterized as involved in EPS size (Becker et al. 1998), which might be important for symbiotic function (Battisti et al. 1992; Wang et al. 1999; Pellock et al. 2000). Indeed, a low molecular weight EPS was isolated from B. japonicum USDA 110, although its relationship with symbiosis, if any, was not studied (Louch and Miller 2001). As previously indicated for LP 3010, EPS from LP 3013 was also retained by a 14.5-kDa cut-off pore diameter dialysis membrane, indicating that its size is bigger than previously reported by Becker and associates (1998) for $\triangle \mathrm{P} 22$, maybe due to ExoT and ExoP activities in LP 3013. Interestingly, when nodule occupation by LP 3013 was forced by the addition of wild-type EPS to the inoculum, suppressor mutants with a similar phenotype to $\Delta \mathrm{P} 22$ were selected; however, the nature of these suppressor mutations is still unknown.

Thus, each galactoside had a different symbiotic role in $B$. japonicum EPS, with galactose being the most determinant for nodule invasion. These results also indicate that, despite being a determinate nodulation system, this symbiosis also requires intact EPS.

\section{MATERIALS AND METHODS}

\section{Bacterial strains, plasmids, and culture conditions.}

The bacterial strains and plasmids used in this study are summarized in Table 3. B. japonicum was grown at $28^{\circ} \mathrm{C}$ and rotary shaking at $180 \mathrm{rpm}$ in liquid Götz minimal medium (Götz et al. 1982) with $27 \mathrm{mM}$ mannitol as sole C-source. The total biomass was estimated from optical density at $500 \mathrm{~nm}$ $\left(\mathrm{OD}_{500}\right)$ and the viable bacteria from the number of $\mathrm{CFU}$ in YMA plates (Vincent 1970). Escherichia coli was grown in Luria-Bertani medium at $37^{\circ} \mathrm{C}$. For E. coli, antibiotic concentrations were ampicillin at $200 \mu \mathrm{g} \mathrm{ml}^{-1}$, gentamycin $(\mathrm{Gm})$ at 10 $\mu \mathrm{g} \mathrm{m} l^{-1}, \mathrm{Km}$ at $25 \mu \mathrm{g} \mathrm{m}{ }^{-1}, \mathrm{Sp}$ at $100 \mu \mathrm{g} \mathrm{m}{ }^{-1}, \mathrm{Sm}$ at $100 \mu \mathrm{g} \mathrm{ml} \mathrm{l}^{-1}$, and tetracycline (Tc) at $10 \mu \mathrm{g} \mathrm{ml}^{-1}$. For B. japonicum, concentrations were $\mathrm{Cm}$ at $20 \mu \mathrm{g} \mathrm{ml}^{-1}, \mathrm{Gm}$ at $100 \mu \mathrm{g} \mathrm{ml}^{-1}, \mathrm{Km}$ at 150 $\mu \mathrm{g} \mathrm{ml}^{-1}, \mathrm{Sp}$ at $200 \mu \mathrm{g} \mathrm{ml} l^{-1}, \mathrm{Sm}$ at $400 \mu \mathrm{g} \mathrm{ml}^{-1}$, and Tc at 100 $\mu \mathrm{g} \mathrm{ml} \mathrm{m}^{-1}$.

\section{DNA manipulations.}

Standard protocols were used for DNA manipulations (Sambrook and Russell 2001). Sequencing was carried out by Macrogen DNA Sequencing Service (Seoul, Korea). The primers employed in this study are summarized in Table 2.

Table 3. Bacterial strains and plasmids used in this study

\begin{tabular}{|c|c|c|}
\hline Strain or plasmid & Relevant genotype or phenotype $^{a}$ & References or source \\
\hline \multicolumn{3}{|l|}{ Strains } \\
\hline \multicolumn{3}{|l|}{ Escherichia coli } \\
\hline DH5 $\alpha$ & recA1, $\Delta l a c \mathrm{U} 169,(\Phi 80 \mathrm{~d} l a c \mathrm{Z} \Delta \mathrm{M} 15)$ & Bethesda Research Laboratory \\
\hline \multicolumn{3}{|c|}{ Bradyrhizobium japonicum } \\
\hline USDA 110 & Wild-type $\mathrm{Nod}^{+} \mathrm{Fix}^{+}\left(\mathrm{Cm}^{\mathrm{r}}\right)$ & USDA culture collection $^{\mathrm{b}}$ \\
\hline$\Delta \mathrm{P} 22$ & USDA $110 \mathrm{spc} 4$ deletional mutant blr 7576, blr7577 and $b \operatorname{lr} 7578\left(\mathrm{Sp}^{\mathrm{r}} \mathrm{Km}^{\mathrm{r}}\right)$ & Becker et al. 1998 \\
\hline LP 3010 & USDA 110 deletional mutant $b \operatorname{lr} 2382$ and $b \operatorname{lr} 2383\left(\mathrm{Sp}^{\mathrm{r}} \mathrm{Sm}^{\mathrm{r}} \mathrm{Cm}^{\mathrm{r}}\right)$ & This study \\
\hline LP 3011 & USDA 110 deletional mutant $b l r 2382$ and $b l r 2383\left(\mathrm{Sp}^{\mathrm{r}} \mathrm{Sm}^{\mathrm{r}} \mathrm{Cm}^{\mathrm{r}}\right)$ & This study \\
\hline LP 3012 & USDA 110 deletional mutant blr2382 and $b \operatorname{lr} 2383\left(\mathrm{Sp}^{\mathrm{r}} \mathrm{Sm}^{\mathrm{r}} \mathrm{Cm}^{\mathrm{r}}\right)$ & This study \\
\hline LP 3013 & USDA 110 insertional mutant $b \operatorname{lr} 7578\left(\mathrm{Km}^{\mathrm{r}} \mathrm{Cm}^{\mathrm{r}}\right)$ & This study \\
\hline LP 3014 & USDA 110 insertional mutant $b l r 7578\left(\mathrm{Km}^{\mathrm{r}} \mathrm{Cm}^{\mathrm{r}}\right)$ & This study \\
\hline LP 3015 & USDA 110 insertional mutant $b l r 7578\left(\mathrm{Km}^{\mathrm{r}} \mathrm{Cm}^{\mathrm{r}}\right)$ & This study \\
\hline LP 3016 & USDA 110 insertional mutant blr7578 $\left(\mathrm{Km}^{\mathrm{r}} \mathrm{Cm}^{\mathrm{r}}\right)$ & This study \\
\hline LP 3017 & LP 3010 insertional mutant $b \operatorname{lr} 7578\left(\mathrm{Sp}^{\mathrm{r}} \mathrm{Sm}^{\mathrm{r}} \mathrm{Km}^{\mathrm{r}} \mathrm{Cm}^{\mathrm{r}}\right)$ & This study \\
\hline \multicolumn{3}{|c|}{ CE- } \\
\hline pRK2013 & Helper plasmid tra ${ }^{+}$oriT, ColE1 $\left(\mathrm{Km}^{\mathrm{r}}\right)$ & Figurski and Helinski 1979 \\
\hline pGEM T-Easy & Multicopy plasmid vector for cloning PCR products $\left(\mathrm{Ap}^{\mathrm{r}}\right)$ & Promega Corp. \\
\hline pK18mob & Suicide plasmid in rhizobia, $\mathrm{Mob}^{+}\left(\mathrm{Km}^{\mathrm{r}}\right)$ & Schäfer et al. 1994 \\
\hline pG18mob2 & Suicide plasmid in rhizobia, $\mathrm{Mob}^{+}\left(\mathrm{Gm}^{\mathrm{r}}\right)$ & Schäfer et al. 1994 \\
\hline pG18mob LK & pG18mob2 with short-length modified multiple cloning site $\left(\mathrm{Gm}^{\mathrm{r}}\right)$ & $\begin{array}{l}\text { M. Pistorio, IBBM, UNLP- } \\
\text { CONICET }\end{array}$ \\
\hline pBBR1MCS2 & Broad-host-range replicative plasmid vector $\left(\mathrm{Km}^{\mathrm{r}}\right)$ & Kovach et al. 1995 \\
\hline pBBR1MCS5 & Broad-host-range replicative plasmid vector $\left(\mathrm{Gm}^{\mathrm{r}}\right)$ & Kovach et al. 1995 \\
\hline $\mathrm{pHP} 45 \Omega$ & Plasmid vector containing an omega $(\Omega) \mathrm{Sm}-\mathrm{Sp}$ interposon $\left(\mathrm{Ap}^{\mathrm{r}} \mathrm{Sm}^{\mathrm{r}} \mathrm{Sp}^{\mathrm{r}}\right)$ & Prentki and Krisch 1984 \\
\hline pCB303 & Replicative plasmid vector $l a c Z$ and $p h o A$ without promoters, oriT $\left(\mathrm{Tc}^{\mathrm{r}}\right)$ & Schneider and Beck 1987 \\
\hline pUC4K & Plasmid with $n p t I$ gene (source for Km-resistance cassette) $\left(\mathrm{Ap}^{\mathrm{r}} \mathrm{Km}^{\mathrm{r}}\right)$ & Vieira and Messing 1982 \\
\hline pIQ05 & pG18mobLK carrying a blr 7578 internal fragment $\left(\mathrm{Gm}^{\mathrm{r}}\right)$ & This study \\
\hline pIQ06 & pIQ05 carrying a pUC4K-nptI gene $\left(\mathrm{Km}^{\mathrm{r}}\right)$ inserted into $b l r 7578$ & This study \\
\hline pIQ08 & pCB303 carrying a complete $b l r 7578$ gene $\left(\mathrm{Tc}^{\mathrm{r}}\right)$ & This study \\
\hline \multirow[t]{2}{*}{ pIQ09 } & pGEM T-Easy carrying an intergenic fragment between bll2381 and blr2382 (A) & \\
\hline & from $2,595,375$ to $2,595,687$ USDA 110 genome nucleotides $\left(\mathrm{Ap}^{\mathrm{r}}\right)$ & This study \\
\hline \multirow[t]{2}{*}{ pIQ10 } & pGEM T-Easy carrying an intergenic fragment between blr2383 and blr2384 (B) & \\
\hline & from $2,598,116$ to $2,597,844$ USDA 110 genome nucleotides $\left(\mathrm{Ap}^{\mathrm{r}}\right)$ & This study \\
\hline pIQ11 & pK18mob carrying the intergenic fragment $\mathrm{A}\left(\mathrm{Km}^{\mathrm{r}}\right)$ & This study \\
\hline pIQ12 & pBBR1MCS5 carrying the intergenic fragment B $\left(\mathrm{Gm}^{\mathrm{r}}\right)$ & This study \\
\hline pIQ13 & pIQ11 carrying the intergenic fragment $\mathrm{B}\left(\mathrm{Km}^{\mathrm{r}}\right)$ & This study \\
\hline pIQ14 & pIQ13 carrying intergenic fragments A and B and a $\Omega-\mathrm{Sm}-\mathrm{Sp}$ interposon between & \\
\hline nIO15 & them $\left(\mathrm{Km}^{\mathrm{r}} \mathrm{Sm}^{\mathrm{r}} \mathrm{Sp}^{\mathrm{r}}\right)$ & This study \\
\hline
\end{tabular}

${ }^{\mathrm{a}} \mathrm{Cm}^{\mathrm{r}}, \mathrm{Km}^{\mathrm{r}}, \mathrm{Sp}^{\mathrm{r}}, \mathrm{Sm}^{\mathrm{r}}, \mathrm{Ap}^{\mathrm{r}}, \mathrm{Gm}^{\mathrm{r}}$, and $\mathrm{Tc}^{\mathrm{r}}=$ resistant to chloramphenicol, kanamycin, spectinomycin, streptomycin, ampicillin, gentamycin, and tetracycline, respectively.

${ }^{\mathrm{b}}$ USDA $=$ United States Department of Agriculture. 
To obtain $l s p L-u g d H$ mutants, a 248-bp fragment upstream of $l s p L$ (fragment A) and a 291-bp fragment downstream of $u g d H$ (fragment B) were amplified by PCR using the primers $\mathrm{lsF}$ and $\mathrm{lsR}$ for fragment $\mathrm{A}$ and $\mathrm{ugF}$ and $\mathrm{ugR}$ for fragment $\mathrm{B}$ (Table 2). The PCR conditions consisted of a first denaturation cycle at $94^{\circ} \mathrm{C}$ for $1 \mathrm{~min}$; then, 35 cycles of denaturation at $94^{\circ} \mathrm{C}$ for $20 \mathrm{~s}$, annealing at $56^{\circ} \mathrm{C}$ for $20 \mathrm{~s}$, and elongation at $72^{\circ} \mathrm{C}$ for $45 \mathrm{~s}$; and, finally, one last elongation cycle at $72^{\circ} \mathrm{C}$ for $2 \mathrm{~min}$. Each fragment was cloned into pGEM-T-easy, giving rise to pIQ09 and pIQ10, respectively. Fragment A was recovered from pIQ09 by EcoRI digestion and ligated into the EcoRI site of pK18mob to obtain pIQ11. The same procedure was used to insert the B fragment into pBBR1MCS5, thus originating pIQ12. This plasmid was digested with BamHI and HindIII and ligated into BamHI-HindIII-digested pIQ11 to generate pIQ13, which carried the A and B fragments in tandem. Finally, a SmaI-digested $\Omega$-Sm-Sp cassette from $\mathrm{pPH} 45 \Omega$ was ligated into $S m a I$-digested pIQ13 to generate the suicide plasmid pIQ14. The construction was confirmed by sequencing and then the plasmid was conjugated into B. japonicum USDA 110 by triparental mating with $E$ coli carrying the helper plasmid pRK2013. Double-crossover events causing Sm-Sp resistance and $\mathrm{Km}$ sensitivity were selected. Three mutants (LP 3010, LP 3011, and LP 3012) were selected and confirmed by PCR using the lsupF and ugdwR primers in combination with $\mathrm{Sm}-\mathrm{Sp}$ primers (Table 2). To complement the mutation, we amplified 3,172 bp containing both the $l s p L$ and $u g d H$ genes, including the putative promoter upstream of $l s p L$, with Pfx DNA polymerase using the primers lsupF and ugdwR (Table 2). The PCR conditions consisted of a first denaturation cycle of $94^{\circ} \mathrm{C}$ for $5 \mathrm{~min}$; then, 35 cycles of denaturation at $94^{\circ} \mathrm{C}$ for $1 \mathrm{~min}$, annealing at $55^{\circ} \mathrm{C}$ for $1 \mathrm{~min}$, and elongation at $68^{\circ} \mathrm{C}$ for 5.5 min; and, finally, one last elongation cycle at $68^{\circ} \mathrm{C}$ for $7 \mathrm{~min}$. This amplicon was inserted into the EcoRV restriction site of the replicative vector pBBR1MCS2. This plasmid, termed pIQ15, was checked by PCR and sequencing and mobilized into $B$. japonicum by conjugation, as before.

To obtain exoB mutants, an internal 686-bp PCR fragment was amplified with the primers exF and exR (Table 2). The PCR conditions consisted of a first denaturation cycle at $94^{\circ} \mathrm{C}$ for $1 \mathrm{~min}$; then, 35 cycles of denaturation at $94^{\circ} \mathrm{C}$ for $20 \mathrm{~s}$, annealing at $56^{\circ} \mathrm{C}$ for $20 \mathrm{~s}$, and elongation at $72^{\circ} \mathrm{C}$ for $45 \mathrm{~s}$; and, finally, one last elongation cycle at $72^{\circ} \mathrm{C}$ for $2 \mathrm{~min}$. This fragment was cloned into pGEM-T-easy and then transferred to pG18mobLK to create pIQ05. This plasmid was digested with PstI, and an nptI Km-resistant cassette obtained by PstI digestion of pUC4-K was inserted to obtain pIQ06. Finally, the construction was checked by sequencing and introduced into B. japonicum USDA 110 by triparental mating, as before. We searched for double-crossover events into exoB by selecting for $\mathrm{Km}$ resistance and $\mathrm{Gm}$ sensitivity among the transconjugants. Selected transconjugants were checked by PCR with $\mathrm{KmF}$ and $\mathrm{KmR}$ primers used in combination with extF and extR (Table 2). In this way, LP 3013, LP 3014, LP 3015, and LP 3016 clones were obtained. To complement these mutants, a fragment of $1,172 \mathrm{bp}$, including the complete $\operatorname{exoB}$ gene with its own putative promoter, was amplified by PCR employing the extF and extR primers and Pfx DNA polymerase. The PCR conditions consisted of a first denaturation cycle at $94^{\circ} \mathrm{C}$ for 4 $\mathrm{min}$; then, 35 cycles of denaturation at $94^{\circ} \mathrm{C}$ for $1 \mathrm{~min}$, annealing at $58^{\circ} \mathrm{C}$ for $50 \mathrm{~s}$, and elongation at $68^{\circ} \mathrm{C}$ for $3 \mathrm{~m}$; and, finally, one last elongation cycle at $68^{\circ} \mathrm{C}$ for $6 \mathrm{~min}$. This amplicon was introduced into the promoterless replicative vector pCB303 (provided by P. Müller, Philipps Universität, Marburg, Germany), thus originating the plasmid pIQ08. This plasmid was checked by sequencing and introduced into $B$. japonicum USDA 110 by triparental mating, as described above. The $B$. japonicum USDA 110 cells carrying pIQ08 turned blue in YMA agar plates supplemented with X-phosphate, thus confirming that the 1,172-bp fragment cloned in the same orientation of promoterless $p h o A$ gene in pIQ08 carried both the exoB promoter and the $e x o B$ coding sequence.

A double mutant in $l s p L-u g d H$ and exoB (LP 3017) also was isolated by recombining pIQ06 into LP 3010 and then screening for Gm-sensitive and Sp-Sm- and Km-resistant clones. All these mutants were confirmed by PCR mapping with the same procedure as used for the mutant LP 3010.

\section{EPS preparation and quantification.}

Cultures of $B$. japonicum $(300 \mathrm{ml})$ were centrifuged at $12,000 \times g$ for $40 \mathrm{~min}$. The EPS was precipitated from the supernatant with three volumes of $96 \%$ ethanol at $-20^{\circ} \mathrm{C}$ and, after resuspension in $0.5 \mathrm{M} \mathrm{NaCl}$, it was quantified with $0.2 \%$ (wt/vol) anthrone in $95 \% \mathrm{H}_{2} \mathrm{SO}_{4}$ against a calibration curve constructed with glucose as the standard (Law and Slepecki 1961).

To determine EPS composition, the above preparations were dialyzed with $3.5-\mathrm{kDa}$ (Spectra/Por) or $14.5-\mathrm{kDa}$ (Sigma) cutoff pore diameter membranes against double-distilled water and lyophilized to concentrate them. To assess the purity of these samples, we weighed them and compared these weights to the expected EPS mass from anthrone determinations (taking into account that anthrone reaction is not identical with all sugars that compose the EPS). In addition, we assessed the possible presence of proteins in the samples trough Bradford (1976) colorimetric determinations.

EPS samples were resuspended in milliQ water and subjected to total hydrolysis with $2 \mathrm{M}$ trifluoroacetic acid at $120^{\circ} \mathrm{C}$ for 2 h. To remove acid remnants, samples were resuspended in milliQ water and evaporated in a rotavapor. This procedure was repeated three times and, finally, the samples were dissolved in milliQ water. In some cases, to assure sugar deacetylation, further treatment with $0.1 \mathrm{~N} \mathrm{MeONa}$ in $\mathrm{MeOH}$ (anh) overnight at room temperature was performed. A DX-300 Dionex BioLC system with a pulse amperometric detector and a Carbopack PA-10 precolumn and column were used for HPAEC-PAD analysis. The following conditions were employed: i) for neutral sugar analysis, an isocratic elution with $7 \%$ solution A (200 mM NaOH), 93\% solution B (water), with a flow rate of $1 \mathrm{ml} \mathrm{min} \mathrm{m}^{-1}$; and ii) for acidic sugar analysis, an isocratic elution with $25 \%$ solution $\mathrm{A}, 65 \%$ solution $\mathrm{B}$, and $10 \%$ solution $\mathrm{C}$ (1 $\mathrm{M} \mathrm{Na}$ acetate), with a flow rate of $1 \mathrm{ml} \mathrm{min}^{-1}$.

\section{LPS preparation and electrophoretic analysis.}

Cultures of B. japonicum (10 ml) were centrifuged at 12,000 $\times g$ for $40 \mathrm{~min}$. The supernatant containing EPS was discarded and the mucoid pellet obtained was washed two times with 0.5 $\mathrm{M} \mathrm{NaCl}$ and then resuspended in phosphate-buffered saline buffer. This suspension was treated in an Omnimixer (Beckmann Instruments (Irvine, CA, U.S.A.) for $1 \mathrm{~min}$ at mean power and kept at $4{ }^{\circ} \mathrm{C}$ for 4 days in order to solubilize the CPS (Mort and Bauer 1980). Then, this suspension was centrifuged at $12,000 \times g$ for $40 \mathrm{~min}$. This time, the centrifugation produced a compact pellet, which was resuspended, and the LPS was isolated by the hot water-phenol method (Westphal and Jann 1965). The water layer containing the LPS was treated with DNase I and RNase A. The sample was then treated with proteinase $\mathrm{K}\left(100 \mu \mathrm{g} \mathrm{m}{ }^{-1}\right)$ at $37^{\circ} \mathrm{C}$ for $1 \mathrm{~h}$. The sample was dialyzed and lyophilized. The lyophilized powder was stored at $4{ }^{\circ} \mathrm{C}$ for further use. Electrophoretic profiles of LPS samples were obtained in SDS-PAGE (polyacrylamide 17.5\%) and silver-stained as described (Hozbor et al. 2004).

LPS was hydrolyzed with acetic acid $1 \%$ and the solution of LPS heated at $100^{\circ} \mathrm{C}$ for $2 \mathrm{~h}$. After centrifugation, the solution 
containing the oligosaccharide moiety (sugar core and the $\mathrm{O}$ antigen) was separated and hydrolyzed.

\section{Biofilm quantification.}

The biofilm assay was based on the method of Fujishige and associates (2006), with some modifications. Cultures were grown in Götz medium to late exponential phase, diluted to an $\mathrm{OD}_{500}$ of 0.1 , and inoculated into the individual wells of a 96well polystyrene plate (Kartell "U" well shape, catalog no. 2621 ) in $150-\mu l$ aliquots. Five plates were covered with a sterile microporous sealing film to allow gas exchange and prevent evaporation and incubated with agitation $(50 \mathrm{rpm})$ at $28^{\circ} \mathrm{C}$ for $1,2,4,7$, and 23 days each. At these defined times, cells were gently resuspended by repeated pipetting of the contents in each well, and bacterial growth was quantified by measuring the $\mathrm{OD}_{500}$ to verify that there were no differences in growth rate among wells and strains. The contents of each well were then removed and washed with distilled water. The plates were emptied, air dried, stained for 15 min with $150 \mu \mathrm{l}$ of $0.1 \%$ crystal violet per well, and then rinsed three times with water. Biofilm formation was quantified by the addition of $150 \mu \mathrm{l}$ of acetone-ethanol (80:20) to each crystal-violet-stained microtiter dish well, and the absorbance $(570 \mathrm{~nm})$ of the solubilized crystal violet was determined with a microplate reader. Bacterial growth and adherence measurements were performed eight times per strain and averaged. The whole experiment was repeated at least three times. Negative controls were performed with Götz medium employed without any bacterial inoculum.

\section{Plant assays.}

The seed of soybean (G. max cvs. Don Mario 4800, Don Mario 3100, Don Mario 4600, and A7321RG and G. soja cv. PI339871A) were provided by A. Perticari (Instituto de Microbiología Zoología Agrícola, Castelar, Argentina). Seed were surface sterilized by immersion in $96 \%$ ethanol for $10 \mathrm{~s}$ and then in $20 \%$ ( $\mathrm{vol} / \mathrm{vol}$ ) commercial bleach for $10 \mathrm{~m}$, followed by six to seven sterile-distilled water washes, and germinated for 4 days on water-agar $(1.5 \% \mathrm{wt} / \mathrm{vol})$ at $28^{\circ} \mathrm{C}$ in darkness.

For infectivity, nodulation profiles were obtained by inoculating 30 plants with the indicated concentrations of rhizobia per milliliter in plastic growth pouches watered with FMS (Lodeiro et al. 2000) as described by Bhuvaneswari and associates (1980). At the time of inoculation, the positions of the smallest emergent root hairs (SERH) and the root tip (RT) were marked for each plant on the surface of the plastic growth pouches. The distance between the SERH and RT marks for each individual plant was taken as the relative distance unit (RDU) for that plant. After 22 days of growth in the greenhouse at 26 and $18^{\circ} \mathrm{C}$ (day and night temperatures, respectively), all nodules appearing on primary roots were counted, and all nodule positions in the primary root of each plant were recorded in millimeters $( \pm 0.5 \mathrm{~mm})$ with respect to the corresponding RT mark. Nodule distances to RT were expressed in RDU to compensate for the different elongation rates and SERH/RT lengths among individual plants. Nodules appearing above the RT mark were given positive values while those appearing below the RT mark received negative values (Bhuvaneswari et al. 1980). The nodule numbers and nodule distances to the RT were expressed as mean values \pm standard error.

To evaluate nodule occupancy, we performed competition experiments by co-inoculating soybean plantlets with mixtures of USDA 110 and LP 3010 in a 1:1 proportion. To this end, plastic pots were surface sterilized with $70 \%$ ethanol and UV irradiation and filled with autoclaved vermiculite. Next, the vermiculite in each pot was filled at field capacity with $700 \mathrm{ml}$ of FMS containing a mixture of both strains at approximately $1.5 \times 10^{5} \mathrm{CFU}$ $\mathrm{ml}^{-1}$ each, freshly prepared by dilution from exponentially grow- ing liquid cultures. Seed germinated as above were transferred, under laminar flow, to the pots in sets of three plants per pot. For competition, nine pots (27 plants) were prepared. As controls, two pots were kept uninoculated and two sets of two pots each were inoculated with each strain alone. After planting, the pots were carried to the greenhouse, where they stayed for 25 days, with watering as required. Then, nodules were excised, surface sterilized, and crushed to obtain the occupying rhizobia, which were sown in YMA with selective antibiotics, as described by López-García and associates (2002). Nodule occupation by LP 3010 was expressed as the proportion of nodules occupied by $\mathrm{Sm}-, \mathrm{Sp}-$, and $\mathrm{Cm}$-resistant rhizobia. For statistical analysis, these values were transformed to the arcsin root square, and analysis of variance was done with the transformed values, employing a significance level of $P<0.05$.

To assess plant growth, in separate experiments, the plants were grown for 63 days in the same conditions, and then the aboveground biomass (shoots plus leaves) was cut, dried to a constant weight in an oven at $60^{\circ} \mathrm{C}$ for 5 days, and weighed individually. Statistical analysis was carried out by analysis of variance with a significance level of $P<0.05$.

Nodule sectioning, staining, and microscopy.

All microscopy analyses were carried out at the Central Microscopy Service of the Faculty of Veterinary Sciences, National University of La Plata, Argentina.

Nodules were excised from plants and then transversally cut in halves and placed in $2 \%$ (vol/vol) glutaraldehyde. Then, nodules were postfixed in $1 \%$ (wt/vol) $\mathrm{OsO}_{4}$ in phosphate buffer for $1 \mathrm{~h}$ at room temperature. The osmium fixation was followed by three 10-min washes in distilled water before an ethanol dehydration series $(50,70,80,90$, and $96 \%$ ethanol, each for approximately $15 \mathrm{~min}$, then $100 \%$ ethanol for $1 \mathrm{~h}$ ). Once dehydrated, the samples were gradually infiltrated with epoxy resin. The samples were then transferred into Beem capsules filled with fresh Epon and placed at 35, 45, and $60^{\circ} \mathrm{C}$ (each temperature for $12 \mathrm{~h}$ ) to polymerize. The material was sectioned with a glass knife using a SuperNova Reichert-J ultramicrotome. For light microscopy, 2- $\mu \mathrm{m}$ thick sections were dried onto glass slides and stained with saturated solution of Toluidine blue. Photographs were taken with a Carl Zeiss Jena light microscope coupled to a Kodak camera. For electron microscopy, 70-nm ultrathin sections were placed on 200mesh copper grids that had been coated with collodion. The sections were stained with 0.5 to $1 \%$ (wt/vol) uranyl acetate for $10 \mathrm{~min}$ and $1 \%(\mathrm{wt} / \mathrm{vol})$ lead citrate for $5 \mathrm{~min}$, washed in distilled water, and air dried. The grids were viewed in a JEM $1200 \mathrm{EX}$ II (Jeol) transmission electron microscope at $80 \mathrm{kV}$, and photographs were taken on Kodak electron image film.

\section{ACKNOWLEDGMENTS}

We thank S. B. Jurado for help with microscopy. Supported by Agencia Nacional de Promoción Científica y Tecnológica (ANPCyT) and Consejo Nacional de Investigaciones Científicas y Técnicas (CONICET), Argentina. J. I. Quelas, E. J. Mongiardini, M. J. Althabegoiti, and J. PérezGiménez are fellows of CONICET, Argentina; J. M. Covelli is a fellow of ANPCyT; and S. L. López-García, A. Couto, and A. R. Lodeiro are members of the Scientific Career of CONICET.

\section{LITERATURE CITED}

Battisti, L., Lara, J. C., and Leigh, J. A. 1992. Specific oligosaccharide form of the Rhizobium meliloti exopolysaccharide promotes nodule invasion in alfalfa. Proc. Natl. Acad. Sci. U.S.A. 89:5625-5629.

Becker, B. U., Kosch, K., Parniske, M., and Müller, P. 1998. Exopolysaccharide (EPS) synthesis in Bradyrhizobium japonicum: Sequence, operon structure and mutational analysis of an exo gene cluster Mol. Gen. Genet. 259:161-171. 
Bhuvaneswari, T. V., Turgeon, B. G., and Bauer, W. D. 1980. Early events in the infection of soybean (Glycine max L. Merr.) by Rhizobium japonicum. I. Localization of infectible root cells. Plant Physiol. 66:10271031

Bolaños, L., Cebrián, A., Redondo-Nieto, M., Rivilla, R., and Bonilla, I 2001. Lectin-like glycoprotein PsNLEC-1 is not correctly glycosylated and targeted in boron-deficient pea nodules. Mol. Plant-Microbe Interact. 14:663-670.

Bolaños, L., Redondo-Nieto, M., Rivilla, R., Brewin, N. J., and Bonilla, I. 2004. Cell surface interactions of Rhizobium bacteroids and other bacterial strains with symbiosomal and peribacteroid membrane components from pea nodules. Mol. Plant-Microbe Interact. 17:216-223.

Bradford, M. M. 1976.. A rapid and sensitive method for the quantitation of microgram quantities of protein utilizing the principle of protein-dye binding. Anal. Biochem. 72:248-254.

Bradley, D. J., Butcher, G. W., and Galfre, G. 1986. Physical association between the peribacteroid membrane and lipopolysaccharide from the bacteroid outer membrane in Rhizobium-infected pea root nodule cells. J. Cell Sci. 85:47-61.

Carrion, M., Bhat, U. R, Reuhs, B., and Carlson, R. W. 1990. Isolation and characterization of the lipopolysaccharides from Bradyrhizobium japonicum. J. Bacteriol. 172:1725-1731.

Cermola, M., Hermann, R., Müller, M., Taté, R., and Favre, R. 1994. Ultrastructural analysis of Rhizobium leguminosarum phaseoli in highpressure cryofixed bean root nodules. J. Struct. Biol. 113:142-147.

Cermola, M., Fedorova, E., Taté, R., Riccio, A., Favre, R., and Patriarca, E. J. 2000. Nodule invasion and symbiosome differentiation during Rhizobium etli-Phaseolus vulgaris symbiosis. Mol. Plant-Microbe Interact. 13:733-741.

Chang, W.-S., Park, K.-M., Koh, S.-C., and So, J.-S. 2008. Characterization of the Bradyrhizobium japonicum galE gene: Its impact on lipopolysaccharide profile and nodulation of soybean. FEMS (Fed. Eur. Microbiol. Soc.) Microbiol. Lett. 280:242-249.

D’Antuono, A. L., Casabuono, A., Couto, A., Ugalde, R. A., and Lepek, V. C. 2005. Nodule development induced by Mesorhizobium loti mutant strains affected in polysaccharide synthesis. Mol. Plant-Microbe Interact. 18:446-457.

Doyle, J. J. 1998. Phylogenetic perspectives on nodulation: Evolving views of plants and symbiotic bacteria. Trends Plant Sci. 3:473-478

Eggleston, G., Huber, M. C., Liang, R., Karr, A. L., and Emerich, D. W. 1996. Bradyrhizobium japonicum mutants deficient in exo- and capsular polysaccharides cause delayed infection and nodule initiation. Mol. Plant-Microbe Interact. 9:419-423.

Fedorova, E., Thomson, R., Whitehead L. F., Maudoux, O., Udvardi, M.K., and Day, D. A. 1999. Localization of $\mathrm{H}^{+}$-ATPases in soybean root nodules. Planta 209:25-32.

Figurski, D. H., and Helinski, D. R. 1979. Replication of an origin-containing derivative of plasmid RK2 dependent on a plasmid function provided in trans. Proc. Natl. Acad. Sci. U.S.A. 76:1648-1652

Fraysse, N., Couderc, F., and Poinsot, V. 2003. Surface polysaccharide involvement in establishing the rhizobium-legume symbiosis. Eur. J. Biochem. 270:1365-1380.

Fujishige, N. A., Kapadia, N. N., De Hoff, P. L., and Hirsch, A. M. 2006. Investigations of Rhizobium biofilm formation. FEMS (Fed. Eur. Microbiol. Soc.) Microbiol. Ecol. 56:195-206.

Götz, R., Limmer, N., Ober, K., and Schmitt, R. 1982. Motility and chemotaxis in two strains of Rhizobium with complex flagella. J. Gen. Microbiol. 128:789-798.

Hirsch, A. M. 1999. Role of lectins (and rhizobial exopolysaccharides) in legume nodulation. Curr. Opin. Plant Biol. 2:320-326.

Hotter, G. S., and Scott, D. B. 1991. Exopolysaccharide mutants of Rhizobium loti are fully effective on a determinate nodulating host but are ineffective on an indeterminate nodulating host. J. Bacteriol. 173:851-859.

Hozbor, D. F., Pich-Otero, A. J. L., Lodeiro, A. R., Del Papa, M. F., Pistorio, M., and Lagares, A. 2004. The symbiotic defect in a Sinorhizobium meliloti lipopolysaccharide mutant can be overcome by expression of other surface polysaccharides. Res. Microbiol. 155:855-860.

Jones, K. M., Kobayashi, H., Davies, B. W, Taga, M. E, and Walker, G. C. 2007. How rhizobial symbionts invade plants: The SinorhizobiumMedicago model. Nat. Rev. Microbiol. 5:619-633.

Kaneko, T., Nakamura, Y., Sato, S., Minamisawa, K., Uchiumi, T., Sasamoto, S., Watanabe, A., Idesawa, K., Iriguchi, M., Kawashima, K. Kohara, M., Matsumoto, M., Shimpo, S., Tsuruoka, H., Wada, T., Yamada, M., and Tabata, S. 2002. Complete genomic sequence of nitrogen-fixing symbiotic bacterium Bradyrhizobium japonicum USDA 110. DNA Res. 9:189-197.

Kannenberg, E. L., and Brewin, N. J. 1994. Host-plant invasion by Rhizobium: The role of cell-surface components. Trends Microbiol. 2:277-283.

Karr, D. B, Liang, R.-T., Reuhs, B. L., and Emerich, D. W. 2000. Altered exopolysaccharides of Bradyrhizobium japonicum mutants correlate with impaired soybean lectin binding, but not with effective nodule formation. Planta 211:218-226.

Kereszt, A., Kiss, E., Reuhs, B. L., Carlson, R. W., Kondorosi, A., and Putnoky, P. 1998. Novel rkp gene clusters of Sinorhizobium meliloti involved in capsular polysaccharide production and invasion of the symbiotic nodule: The $r k p K$ gene encodes a UDP-glucose dehydrogenase. J. Bacteriol. 180:5426-5431.

Kovach, M. E., Elzer, P. H., Hill, D. S., Robertson, G. T., Farris, M. A Roop, R. M., and Peterson, K. M. 1995. Four new derivatives of the broad-host range cloning vector pBBR1MCS, carrying different antibiotic-resistance cassettes. Gene 166:175-176.

Laus, M. C., Logman, T. J., Van Brussel, A. A., Carlson, R. W., Azadi, P., Gao, M. Y., and Kijne, J. W. 2004. Involvement of exo5 in production of surface polysaccharides in Rhizobium leguminosarum and its role in nodulation of Vicia sativa subsp. nigra. J. Bacteriol. 186:6617-6625.

Law, J. H., and Slepecky, R. A. 1961. Assay of poly-hydroxybutyric acid. J. Bacteriol. 82:33-36.

Leigh, J. A., and Coplin, D. L. 1992. Exopolysaccharides in plant-bacterial interactions. Annu. Rev. Microbiol. 46:307-346.

Lodeiro, A. R., González, P., Hernández, A., Balagué, L. J., and Favelukes, G. 2000. Comparison of drought tolerance in nitrogen-fixing and inorganic nitrogen-grown common beans. Plant Sci. 154:31-41.

López-García, S., Vázquez, T. E. E., Favelukes, G., and Lodeiro, A. R. 2002. Rhizobial position as a main determinant in the problem of competition for nodulation in soybean. Environ. Microbiol. 4:216-224.

Louch, H. A., and Miller, K. J. 2001. Synthesis of a low-molecular-weight form of exopolysaccharide by Bradyrhizobium japonicum USDA 110. Appl. Environ. Microbiol. 67:1011-1014.

Manen, J.-F., Simon, P., Van Slooten, J.-C., Østerås, M, Frutiger, S., and Hughes, G. J. 1991. A Nodulin specifically expressed in senescent nodules of winged bean is a protease inhibitor. Plant Cell 3:259-270.

Mongiardini, E. J., Pérez-Giménez, J., Althabegoiti, M. J., Covelli, J., Quelas, J. I., López-García, S. L., and Lodeiro, A. R. 2009. Overproduction of the rhizobial adhesin RapA1 increases competitiveness for nodulation. Soil Biol. Biochem. 41:2017-2020.

Mort, A. J., and Bauer, W. D. 1980. Composition of the capsular and extracellular polysaccharides of Rhizobium japonicum. Changes with culture age and correlations with binding of soybean seed lectin to the bacteria. Plant Physiol. 66:158-163.

Mort, A. J., and Bauer, W. D. 1982. Application of two new methods for cleavage of polysaccharides into specific oligosaccharide fragments. J. Biol. Chem. 257:1870-1875

Müller, P., Ahrens, K., Keller, T., and Klaucke, A. 1995. A TnphoA insertion within the Bradyrhizobium japonicum sipS gene, homologous to prokaryotic signal peptidases, results in extensive changes in the expression of PBM-specific nodulins of infected soybean (Glycine max) cells. Mol. Microbiol. 18:831-840.

Niehaus, K., Kapp, D., and Pühler, A. 1993. Plant defense and delayed infection of alfalfa pseudonodules induced by an exopolysaccharide (EPSI-deficient Rhizobium meliloti mutant. Planta 190:415-425.

Niehaus, K., Baier, R., Kohring, B., Flashl, E., and Pühler, A. 1997. Symbiotic suppression of the Medicago sativa plant defence system by Rhizobium meliloti oligosaccharides. Pages 110-114 in: Biological Fixation of Nitrogen for Ecology and Sustainable Agriculture. A. Legoki, H Bothe, and A. Pühler, eds. Springer Verlag, Heidelberg, Germany.

Parada, M., Vinardell, J. M., Ollero, F. J., Hidalgo, A., Gutiérrez, R., Buendía-Clavería, A. M., Lei, W., Margaret, I., López-Baeno, F. J., GilSerrano. A. M., Rodríguez-Carvajel, M. A., Moreno, J., and Ruiz-Sainz, J. E. 2006. Sinorhizobium fredii HH103 mutants affected in capsular polysaccharide (KPS) are impaired for nodulation with soybean and Cajanus cajan. Mol. Plant-Microbe Interact. 19:43-52.

Parniske, M., Kosch, K., Werner, D., and Müller, P. 1993. ExoB mutants of Bradyrhizobium japonicum with reduced competitiveness for nodulation of Glycine max. Mol. Plant-Microbe Interact. 6:99-106.

Parniske, M., Schmidt, P. E., Kosch, K., and Müller, P. 1994. Plant defense response of host plants with determinate nodules induced by EPS defective exoB mutants of Bradyrhizobium japonicum. Mol. PlantMicrobe Interact.. 7:631-638.

Patriarca, E. J., Tatè, R., Ferraioli, S., and Iaccarino, M. 2004. Organogenesis of legume root nodules. Int. Rev. Cytol. 234:201-262.

Pellock, B. J., Cheng, H. P., and Walker, G. C. 2000. Alfalfa root nodule invasion efficiency is dependent on Sinorhizobium meliloti polysaccharides. J. Bacteriol. 182:4310-4318.

Pérez-Giménez, J., Mongiardini, E. J., Althabegoiti, M. J., Covelli, J., Quelas, J. I., López-García S. L., and Lodeiro, A. R. 2009. Soybean lectin enhances biofilm formation by Bradyrhizobium japonicum in the absence of plants. Int. J. Microbiol. doi:10.1155/2009/719367. Published online.

Prentki, P., and Krisch, H. M. 1984. In vivo insertional mutagenesis with a selectable DNA fragment. Gene 29:303-313. 
Puvanesarajah, V., Schell, F. M., Gerhold, D., and Stacey, G. 1987. Cell surface polysaccharides from Bradyrhizobium japonicum and a nonnodulating mutant. J. Bacteriol. 169:137-141.

Quelas, J. I., López-García, S. L., Casabuono, A., Althabegoiti, M. J., Mongiardini, E. J., Pérez-Giménez, J., Couto, A., and Lodeiro, A. R. 2006. Effects of N-starvation and C-source on Bradyrhizobium japonicum exopolysaccharide production and composition, and bacterial infectivity to soybean roots. Arch. Microbiol. 186:119-128.

Rinaudi, L. V., and González, J. E. 2009. The low-molecular-weight fraction of exopolysaccharide II from Sinorhizobium meliloti is a crucial determinant of biofilm formation. J. Bacteriol. 191:7216-7224.

Sambrook, J., and Russell, D. 2001. Molecular Cloning: A Laboratory Manual, 3rd ed. Cold Spring Harbor Laboratory Press, Cold Spring Harbor, NY, U.S.A.

Sarma, A. D., and Emerich, D. W. 2005. Global protein expression pattern of Bradyrhizobium japonicum bacteroids: A prelude to functional proteomics. Proteomics 5:4170-4184.

Schäfer, A., Tauch, A., Jäger, W., Kalinowski, J., Thierbach, G., and Pühler, A. 1994. Small mobilizable multi-purpose cloning vectors derived from the Escherichia coli plasmids pK18 and pK19: Selection of defined deletions in the chromosome of Corynebacterium glutamicum. Gene 145:69-73.

Schneider, K., and Beck, C. F. 1987. New expression vectors for identifying and testing signal structures for initiation and termination of transcription. Methods Enzymol. 153:452-461.

Skorupska, A., Janczarek, M., Marczak M., Mazur, A., and Król, J. 2006. Rhizobial exopolysaccharides: Genetic control and symbiotic functions. Microb. Cell Factories 5:7 doi:10.1186/1475-2859-5-7. Published online.
Stanley, J., Longtin, D., Madrzak, C., and Verma, D. P. S. 1986. Genetic locus in Rhizobium japonicum (fredii) affecting soybean root nodule differentiation. J. Bacteriol. 166:628-634.

van Rhijn, P., Goldberg R. B., and Hirsch, A. M. 1998. Lotus corniculatus nodulation specificity is changed by the presence of a soybean lectin gene. Plant Cell 10:1233-1249.

Vandenbosch, K. A., Noel, K. D., Kaneko, Y., and Newcomb, E. H. 1985. Nodule initiation elicited by noninfective mutants of Rhizobium phaseoli. J. Bacteriol. 162:950-959.

Vieira, J., and Messing, J. 1982. The pUC plasmids, an M13mp7-derived system for insertion mutagenesis and sequencing with synthetic universal primers. Gene 19:259-268.

Vincent, J. M. 1970. A Manual for the Practical Study of the Root Nodule Bacteria. IBP Handbook No. 15. Blackwell Scientific Publications, Oxford, U.K.

Wang, L.-X., Wang Y., Pellock B. J., and Walker, G. C. 1999. Structural characterization of the symbiotically important low-molecular-weight succinoglycan of Sinorhizobium meliloti. J. Bacteriol. 181:6788-6796.

Westphal, O., and Jann, K. 1965. Bacterial lipopolysaccharides. Methods Carbohydr. Chem. 5:83-91.

\section{AUTHOR-RECOMMENDED INTERNET RESOURCES}

Berkeley Drosophila Genome Project neural network promoter prediction (NNPP) server: www.fruitfly.org/seq_tools/promoter.html

Comprehensive Microbial Resource (CMR) website: cmr.jcvi.org/tigr-scripts/CMR/CmrHomePage.cgi

Softberry prediction programs: www.softberry.com 